\title{
Tissue-specific Tregs in cancer metastasis: opportunities for precision immunotherapy
}

\author{
Laura A. Huppert ${ }^{1}$, Michael D. Green ${ }^{2,3}$, Luke Kim ${ }^{4}$, Christine Chow ${ }^{1}$, Yan Leyfman ${ }^{5}$, Adil I. Daud ${ }^{1,6}$ and James C. Lee (iD ${ }^{1,6}{ }^{\bowtie}$
}

(c) The Author(s) 2021

Decades of advancements in immuno-oncology have enabled the development of current immunotherapies, which provide longterm treatment responses in certain metastatic cancer patients. However, cures remain infrequent, and most patients ultimately succumb to treatment-refractory metastatic disease. Recent insights suggest that tumors at certain organ sites exhibit distinctive response patterns to immunotherapy and can even reduce antitumor immunity within anatomically distant tumors, suggesting the activation of tissue-specific immune tolerogenic mechanisms in some cases of therapy resistance. Specialized immune cells known as regulatory $T$ cells (Tregs) are present within all tissues in the body and coordinate the suppression of excessive immune activation to curb autoimmunity and maintain immune homeostasis. Despite the high volume of research on Tregs, the findings have failed to reconcile tissue-specific Treg functions in organs, such as tolerance, tissue repair, and regeneration, with their suppression of local and systemic tumor immunity in the context of immunotherapy resistance. To improve the understanding of how the tissue-specific functions of Tregs impact cancer immunotherapy, we review the specialized role of Tregs in clinically common and challenging organ sites of cancer metastasis, highlight research that describes Treg impacts on tissue-specific and systemic immune regulation in the context of immunotherapy, and summarize ongoing work reporting clinically feasible strategies that combine the specific targeting of Tregs with systemic cancer immunotherapy. Improved knowledge of Tregs in the framework of their tissue-specific biology and clinical sites of organ metastasis will enable more precise targeting of immunotherapy and have profound implications for treating patients with metastatic cancer.

Keywords: Tissue Tregs; Immunotherapy; Organ-specific tolerance; Metastasis; Cancer

Cellular \& Molecular Immunology (2022) 19:33-45; https://doi.org/10.1038/s41423-021-00742-4

\section{INTRODUCTION}

In immuno-oncology, recent progress and efforts spanning a century have led us to the present state of cancer immunotherapy [1-3]. Today, cancer drugs that harness the immune system can completely and eradicate solid tumors long-term to achieve cures of even in stage IV cancer. In cancer, nondeleterious "passenger" mutations accumulate in tumor cells over time, and these "alteredself" neoantigens increase immunogenicity, which can lead to antitumor immune recognition $[4,5]$. Checkpoint inhibitors (CPIs) take advantage of this preexisting immunity and induce cytotoxic $\mathrm{T}$ cell attacks on tumor cells. Microsatellite instability-high (MSI-H) cancers and melanoma are among the cancers with the highest tumor mutation burden (TMB), which correlates with their profound and durable response to $\mathrm{CPIs}[6,7]$. However, with the excepts of melanoma and MSI-H cancers, fewer than fifteen percent of cancer patients receive this level of benefit from immunotherapy [6-8]. Unexpectedly, in certain cancers, such as non-small cell lung cancer (NSCLC), CPIs do not reach a level of high efficacy or long-term response despite a high TMB, and the median overall survival (OS) is usually less than 20 months. The variability in CPI response across cancer types can be attributed to various intrinsic and extrinsic mechanisms of resistance in the tumor. However, in melanoma, MSI-H, kidney, and certain other malignancies where CPIs have shown potent efficacy, clinical evidence suggests that the presence of metastases in specific organs, such as the liver, is associated with reduced immunotherapy response and survival [9-12]. These observations suggest the possibility that tissue site-specific factors may impact antitumor effector function, regardless of the level of immune recognition or T cell reinvigoration by CPIs $[13,14]$.

Interestingly, there is tissue site variability in CPI efficacy and autoimmune toxicities [15-17]. Within each tissue, there are potential differences in thresholds and determinants for immune activation because of differences in biological function and involvement in host defense. Tissues resistant to therapy exhibit an inability to break through this tolerance despite a checkpoint blockade. In cases of toxicity, tissue-specific patterns in loss of tolerance likely tilt the immune balance toward excessive activation and aberrant autoimmune attack. The clinical differences and putative mechanisms that govern tissue-specific autoimmune CPI toxicity constitute an area of active investigation and have been recently reviewed by Young et al. and Kang et al.,

\footnotetext{
'Division of Hematology/Oncology, Department of Medicine, University of California, San Francisco, San Francisco, CA, USA. ${ }^{2}$ Department of Radiation Oncology, University of Michigan School of Medicine, Ann Arbor, MI, USA. ${ }^{3}$ Veterans Affairs Ann Arbor Healthcare System, Ann Arbor, MI, USA. ${ }^{4}$ University of California, San Francisco School of Medicine,
}

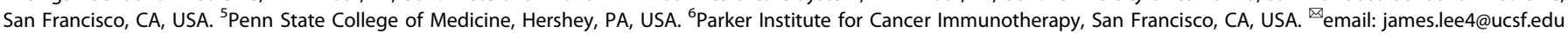


respectively $[17,18]$. There is a growing awareness that tumors within organs are populated with tissue-adapted immune cell subsets, evolutionarily driven by their particular biological function within the organ. Recent work by our group and others revealed organ-specific tolerance mechanisms that not only shape local antitumor immunity but also exert a significant influence on a distant site, potentially through a coordinated tolerogenic effect [19-21]. Currently, neither tumor-intrinsic nor tumorextrinsic resistance pathways are clearly understood in the context of the specialized, tissue-specific microenvironment [22]. It is likely that future therapeutic strategies to overcome resistance mechanisms will need to reconcile tissue-specific factors to be successful.

Specialized immune cells known as regulatory T cells (Tregs) reside in the systemic circulatory system and within all tissues. They are known as the master controllers of self-tolerance and function to maintain immune homeostasis and coordinate the suppression of excessive immune activation to prevent autoimmune responses. The observation that these potent suppressive T cells are also ubiquitous in tumors, or "altered-self" tissues, was first described by Robert North in 1980 [23]. However, although Tregs constitute an immune cell subset that has been among the most extensively studied in oncology for decades, the successful targeting of Tregs for cancer immunotherapy has been elusive because these cells are seldom studied in the context of their critical tissue-specific properties. Emerging evidence suggests that Tregs demonstrate remarkable adaptability to their local environment and facilitate immune homeostasis through highly specialized tissue-specific pathways [24]. After the effective elimination of pathogenic threats, the evolutionarily evolved immune system immediately restores quiescence and prevents further harm [25]. After tumors acquire neoantigens to induce an immune response, potent immune suppressors, such as Tregs, are typically upregulated. Tolerogenic Treg mechanisms have coevolved with specialized biological functions in each organ, and different strategies are required to achieve tumor immunity (Fig. 1). Therefore, a major challenge for effective precision cancer immunotherapy of metastatic disease is the decoding and understanding of the tissue-adapted, multilayered, regulatory processes that have explicitly evolved to protect the various tissue sites coopted in cases of metastatic cancer.

With this review, we aim to improve the understanding of Tregs in the framework of their tissue-specific function and secondary impact on metastasis immunity in hopes of advancing more precise targeting of immunotherapy for metastatic cancer. We begin with a primer on the latest understanding of how Tregs modulate tissue repair and wound healing and how these pathways, shared across tissues, contribute to cancer metastasis. Then, we focus on the tissue-specialized role of Tregs in several clinically relevant cancer metastasis sites, including the liver, bone, skin, lungs, brain, adrenal gland, and lymph nodes (LN). For each organ, we highlight findings from recent work describing the specialized biology of Tregs and their implications for tumor immunity and immunotherapy within that tissue. Finally, we close with a summary of recent advances in several translational treatment strategies that combine the targeting of tissue-specific Tregs with systemic cancer immunotherapy.

\section{TREGS IN TISSUE REPAIR AND CANCER METASTASIS}

There is mounting evidence suggesting that, in addition to peripheral tolerance, Tregs are critical regulators of tissue repair and wound healing across tissues. This critical function is highly evolutionarily conserved, as even zebrafish FoxP3-expressing Tregs are recruited to injured tissue [26]. In mammalian skin, inflammation following injury is necessary to protect against infection, but excessive inflammation and subsequent myeloid cell infiltration may impair wound healing [27]. After skin injury,



Fig. 1 The kinetics of cancer immune responses. Tissues may have different thresholds of immune activation and tolerance. (0) At a steady state, without infection, injury, or tumor, tissues are in immune homeostasis and are populated by tissue-specific resident immune cells. (1) Cancer cells are often initially invisible to local immune surveillance. Due to the lack of neoantigens and inflammatory signals, these cells can be perceived as "self" by tissue-resident immune cells. (2) Tumor cells gain mutations over time, forming neoantigens, making them more visible to local immune surveillance. However, different tissues have different thresholds of immune activation, a system that has been adapted to support their function. (3) When the activation threshold is met, tumor cells are visible to immune surveillance and subject to $T$ cell attack. In this context, different tissues may exhibit different tolerance levels for maximal immune activation, resulting in variable limits of "potential energy" that is generated. (4) In some tissues, as T cells attack the tumor, the "kinetic energy" may never reach adequate levels because the assault is halted by potent tissueadapted negative immune feedback mechanisms such as immune checkpoints and Tregs. CPIs can reverse immunosuppression, but only in a minority of cases. Additional intervention, such as tissuespecific targeting of Tregs, is needed to induce full antitumor immunity. (5) After induction of local antitumor immunity, when the "kinetic energy" of the response is depleted, the tissue returns to a homeostatic state. In some tissues, the cancer is eradicated at this point, but in other tissues, such as the liver, cancer cells typically remain, causing Tregs to repeatedly reinforce homeostasis, ultimately causing a wound that does not heal.

activated CD25, CTLA-4, and ICOS ${ }^{\text {hi }}$ Tregs are recruited from secondary lymphoid organs (SLOs) $[26,28]$. Mice depleted of Tregs in the five days following wounding displayed significantly greater wound closure time than wild-type mice, with the Treg-depleted mice exhibiting increased granulation tissue and size of the resulting eschar, suggesting the importance of early Treg action following skin wounding [29]. Skin-resident Tregs express the transcription factors IRF4 and GATA-3, which suppress $\mathrm{T}_{\mathrm{H}} 2$ immune responses. A number of inflammatory mediators, such as IL-18, IL-33, and thymic stromal lymphopoietin, are released after tissue damage. These molecules stimulate Treg-induced expression of amphiregulin (AREG), a member of the epithelial growth factor (EGF) family that promotes epithelial regeneration and keratinocyte differentiation [30,31]. AREG-dependent production of transforming growth factor- $\beta$ (TGF- $\beta$ ) was found in an acute tissue injury-induced pericyte-to-myofibroblast differentiation and proliferation postinjury model [31-33]. Studies with mice depleted of Tregs prior to injury further suggest that this process is modulated by the growth and differentiation factor activin [29]. Tregs directly suppress the inflammation during tissue repair by altering the wound cytokine profile. Upon Treg depletion in a mouse model of skin injury, the number of conventional IFNY- or IL-17-producing a $\beta$ T cells increased within the wound and were associated with the significant elevation of cytokine IL-4, which impairs cutaneous wound healing by repressing the expression of 


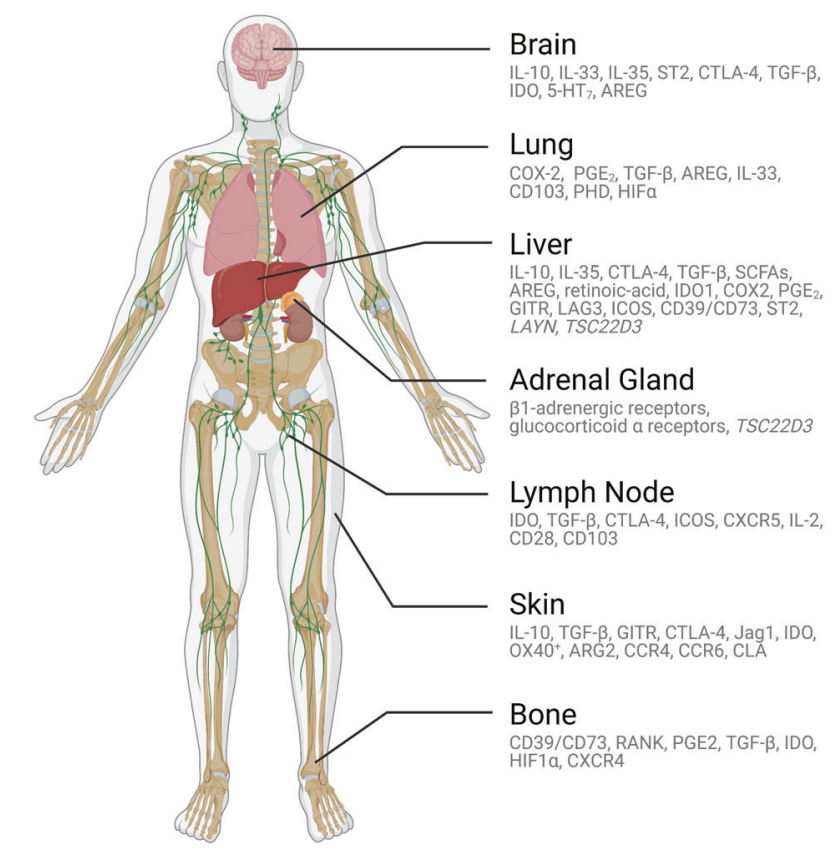

Fig. 2 Tissue-specific regulatory $\mathrm{T}$ cell (Treg) mediators. Tregs in different organs serves distinctive functions via different mediators. In addition to maintaining self-tolerance, Tregs have adapted organspecific specialized functions that support tissue but contribute to ineffective antitumor immunity. From top to bottom: Tregs in the brain express neurotransmitter receptors, respond to microglial cells to dampen autoimmunity, and facilitate neuronal injury repair, including in ischemic injury repair. Tregs in the lungs can express oxygen-sensing proteins, mediate tolerance to inhaled aeroallergens and type 2 immunity against commensals, and support tissue repair and remodeling after airway infections. Tregs in the liver can respond to microbiota-derived metabolites, mediate dietary oral tolerance, regulate immunity to gut commensals, support tissue repair and regeneration, and possibly maintain hematopoietic stem cell quiescence during fetal development. Tregs in the adrenal gland express glucocorticoid receptors and may respond to stress response signaling. Tregs in lymph nodes maintains tolerance by controlling $\mathrm{T}$ follicular helper cells and B cells. Tregs in the skin dampen autoimmunity, regulate tolerance to commensals, mediate wound healing, and support hair growth. Finally, Tregs in the bone maintain hematopoietic stem cell quiescence and facilitate osteogenesis.

fibronectin, an extracellular matrix protein that promotes keratinocyte migration and wound closure [29,34].

In muscle tissue repair, Tregs modulate macrophage differentiation. Following muscle injury, the population of proinflammatory Ly $6 \mathrm{c}^{\mathrm{hi}}$ and $\mathrm{CD} 11 \mathrm{~b}^{+} \mathrm{Gr} 1^{-}$myeloid mononuclear cells was substantially increased, but by the fourth-day postinjury, the population of these cells was decreased, and the population of antiinflammatory Ly6c ${ }^{10}$ cells was increased [35] Treg ablation in post-myocardial infarction (MI) mouse model of acute skeletal muscle injury resulted in the failure of myeloid cell lines within the wound infiltrate to switch from expressing a proinflammatory M1 phenotype to an anti-inflammatory $M 2$ phenotype, impairing cardiac muscle remodeling and post-MI recovery $[35,36]$. Finally, injured skeletal muscle in Treg-depleted mice lacked regenerative muscle fibers and exhibited decreased muscle progenitor cells. AREG expressed by Tregs mediates muscle regeneration by enhancing myosatellite cell differentiation [35].

Tumor cells cause local destruction and inflammation as they proliferate within the tissue, and some are even capable of tumor cell-intrinsic inflammatory signaling [37]. The repeated injury and inflammation induced by unchecked tumor growth drive a vicious cycle that becomes difficult to stop. From the perspective of the tumor microenvironment (TME) and the metastatic niche, the multilayered Treg mechanisms for tissue repair can be coopted to promote cancer progression because they simultaneously prepare the local "soil" for tumor regeneration and growth while protecting the "seed" against immune rejection. Thus, there has been great interest in understanding the role of Tregs in cancer growth and proliferation within the TME [38]. Tregs have been extensively studied in the peripheral blood and immune infiltrates of different cancers, and a higher Treg-to-effector $\mathrm{T}$ cell ratio within tumor tissue is associated with worse patient prognoses in many tumor types, including melanoma, pancreatic ductal adenocarcinoma [39], NSCLC [40], ovarian cancer [41,42], glioblastoma [43], non-Hodgkin lymphoma [44], and others.

Research on the link between the direct role of Tregs in cancer metastasis is ongoing and active. Tumor-infiltrating Tregs generally express higher levels of cell surface molecules associated with $T$ cell activation, such as CD25, CTLA-4, PD-1, LAG3, TIGIT, ICOS, 4-1BB, OX-40, and GTFR [45]. These cells are thought to suppress effector $T$ cells directly, contribute to the metabolic disruption of effector $\mathrm{T}$ cells, and modulate the maturation and function of dendritic cells required for effector $\mathrm{T}$ cell activation [46]. Tregs are also thought to play a role in promoting tumor metastases by facilitating tumor dissemination, immune evasion, and preparing metastatic foci [47]. For example, increased Treg frequencies are associated with a greater risk of metastasis in many cancers, including breast, ovarian, prostate, lung, thyroid, gastric, colorectal, and skin cancers [47-49]. Higher levels of tumor-infiltrating Tregs are associated with increased tumor size, while increased proportions of peripheral blood Tregs are associated with clinical stage, pathological differentiation, and LN metastasis [50]. We summarize key mediators of Treg biology (Fig. 2) and highlight the latest research on these processes in the context of their specialized, tissue-specific functions within each clinically relevant site of cancer metastasis.

\section{TREGS IN LUNG METASTASIS}

Experimental studies have shown that Tregs have a central function in maintaining immune homeostasis in healthy lungs. This finding is not surprising, as the respiratory tract has evolved to interface with the environment and has an impressive alveolar surface area of $\sim 70 \mathrm{~m}^{2}$ in adult humans that can be subjected to constant exposure to environmental antigens during respiration, making control of local immune homeostasis a tightly regulated process [51]. An acute inflammatory response after infection or injury that remains unresolved can lead to an immediately lifethreatening impairment of alveolar oxygen exchange, making immunoregulation critical [52]. Under physiological conditions, Tregs are thought to mediate tolerance of inhaled innocuous environmental aeroallergens, type 2 immunity in response to commensals, and subsequent IgE production [26,51]. The alarmin IL-33, produced by lung cells after exposure to allergens, induces mast cells to produce IL-2, which expands the Treg population within the lungs [53]. Failure of Treg suppression of the chronic immune response to aeroallergens has been attributed to airway tissue remodeling and is a hallmark of asthma [51]. In addition, Treg expression of the EGF family member AREG is critical in pulmonary tissue repair after airway infections and is apparently IL-33-dependent but TCR-independent [54].

Lung cancer is the leading cause of cancer-associated deaths worldwide, with $85 \%$ of cases due to NSCLC and $15 \%$ of cases due to SCLC. Exposure to tobacco smoke, environmental carcinogens, and inflammatory lung disease are all risk factors, and it is thought that these inflammatory states alter inflammatory cytokine levels, oxidative stress markers, and immune cell composition. Despite reports suggesting that the lungs are sites of improved CPI response in metastatic disease, immune escape plays a major role in the development and progression of primary lung cancer and 
metastasis, and it is thought that Tregs are recruited to the tumor tissue and facilitate tumor cell escape from immunological surveillance $[15,55]$. Specifically, Tregs can induce immunosuppression through contact-independent mechanisms such as the sequestration of IL-1 and the production of soluble immunosuppressive molecules such as TGF- $\beta$, IL-10, prostaglandin E2, IL-10, and galectin- 1 and contact-dependent mechanisms such as the expression of cytotoxic T-lymphocyte-associated protein-4 (CTLA4), programmed cell death-1 (PD-1), programmed death-ligand one (PD-L1), lymphocyte-activation protein-3 (LAG-3), and neuropilin 1 (NRP1) [56-58].

Preclinical work has suggested that Tregs play an important role in the early stages of lung tumor development. In murine models of mutant Kras-driven lung adenocarcinoma, tumorigenesis was dependent on Tregs, and Kras transgenic mice that were deficient in FoxP3 ${ }^{+}$Tregs developed $75 \%$ fewer lung tumors than wild-type mice [59]. Tregs are also thought to play a role in the TME during the development and progression of lung cancers. Murine models of lung adenocarcinoma have revealed that Tregs likely play a role in inhibiting CD8 T cell-mediated antitumor immunity, as depletion of Tregs has been associated with tumor cell death and elevated levels of IFNy, granzyme A, granzyme B, and perforin in infiltrating CD8 T cells [60]. In SCLC cell lines, Treg generation is induced by CD4 T cells through the production of IL-15, further supporting the notion that tumor cells can manipulate Tregs to their advantage [61].

In addition to enabling tumor growth and development, Tregs have also been suggested to promote the development of metastatic tumor foci. In a study of 23 patients with NSCLC, Treg levels in the peripheral blood increased with tumor stage and were highest in patients with metastatic disease [62]. Interestingly, the Restifo group showed that the lung may be a tumorpermissive organ due to the tissue-specific expression of oxygensensing prolyl-hydroxylase (PHD) proteins in a preclinical model and that changes in extracellular oxygen tension induced Treg quantity and function through an increase in PHD proteins and a local reduction in HIF1a, which correlated with increased intrapulmonary metastasis [63].

Prognostically, there is a growing body of literature suggesting that high Treg infiltration predicts the risk of recurrence and clinical outcomes. For example, patients with SCLC with higher ratios of Tregs in the tumor infiltrate exhibited worse OS [61]. In NSCLC, elevated levels of cyclooxygenase-2 (COX-2), which transforms Tregs, have been associated with significantly worse recurrence-free survival than observed in patients with low COX-2 tumor expression [64]. Similarly, in a study of 64 patients with stage I NSCLC, patients who had a higher proportion of tumor Tregs relative to tumor-infiltrating lymphocytes showed a significantly higher risk of recurrence [65].

There has also been interesting in evaluating whether the frequency of Tregs can predict response and resistance to immunotherapy in lung cancer. In a recent study by Koh et al., the frequency of circulating Tregs was assessed one week after anti-PD-1 immunotherapy was administered to patients with NSCLC, and the data were correlated with clinical outcomes such as progression-free survival (PFS) and OS. This group found that the frequency of FoxP3 ${ }^{+}$Tregs and TGF- $\beta$ predicts the response to anti-PD1 immunotherapy: The cohort with a high frequency of circulating Tregs 1 week after receiving anti-PD1 therapy had a significantly longer PFS (1.7 months vs. 7.9 months, $P=0.008)$ and OS (4.6 months vs. 12.3 months, $P=0.01$ ) than those with a low frequency of circulating Tregs. In contrast to Tregs, which are thought to enable tumor proliferation, Th17 cells are $\mathrm{CD}^{+}{ }^{+} \mathrm{T}$ helper cells that prevent the expansion of malignant cells in the TME and modulate antitumor immune responses [66]. In lung cancer, tumors with a higher ratio of Tregs to Th17 cells were shown to be associated with more aggressive biological responses and rapid tumor proliferation [67]. The Treg/Th17 ratio has also been studied in pleural fluid and blood [68]. Collectively, these data suggest that specialized Tregs are important for promoting the development, progression, and metastasis of lung cancer and may be clinically relevant for evaluating lung cancer prognosis and an important target for treating lung metastasis.

\section{TREGS IN BONE METASTASIS}

The skeletal system, including the bone marrow (BM), is a unique microenvironment. It is the primary site of hematopoiesis and is critical for the production of innate and adaptive immune cells [69]. Therefore, skeletal tissue where immune responses need to be tightly regulated and controlled to prevent autoimmune reactions. For all cancers, bone is consistently reported to be among the top three most common organs for metastases [70]. Metastasis to the bone is correlated with a poor response to immunotherapy across several cancer types [12]. Data from the Checkmate 057 study, a phase III trial comparing nivolumab to docetaxel as second-line therapy in NSCLC, patients with bone involvement were less responsive to treatment [71]. For prostate and breast cancers, bone is the most common metastatic site, occurring in $70-80 \%$ of cases in patients with advanced disease $[69,72]$. Immunotherapy has shown minimal efficacy against both diseases, with response rates to PD-1-based monotherapy generally less than $10 \%[73,74]$. Recently, the Sharma group reported data from a phase II trial (NCT02985957) that demonstrated that in patients with prostate cancer metastasized to bone, the CPI response rate was only 4\% [75]. Since the prostate and breast are the two most common cancers, there is an urgent need to understand barriers to immunotherapy response.

Given the above, there is reason to speculate that the bone microenvironment may uniquely suppress immunotherapy. Tregs are essential for the maintenance of homeostasis in this dynamic environment. In the BM niche, potent specialized CD150 hi Tregs facilitate the maintenance of hematopoietic stem cell (HSC) quiescence and longevity through adenosine generated by exonucleotidases CD39 and CD73, and BM Tregs are present in significantly higher levels than LN Tregs under physiological conditions [76]. Their presence can be disrupted by blocking CXCR4, which is required for Treg re-entry into the BM, and Tregspecific ablation of CD39 was shown to abrogate the Treg suppressive effect. Notably, even allo-HSCs are protected by BM Tregs, and allo-HSCs were rapidly lost after the depletion of Tregs in a mouse transplant model [77]. Furthermore, Tregs are known to tilt the balance between osteoclasts and osteoblasts toward osteogenesis by suppressing osteoclast differentiation and function, a process that may favor the formation of the osteoblastic bone lesions seen in prostate cancer [78].

In metastatic disease, Tregs further migrate to the tumorassociated $B M$ via the CXCR4/CXCL12 signaling pathway, and $\mathrm{RANK}^{+} \mathrm{DCs}$ induce Treg cell expansion [78]. In a preclinical model of castration-resistant prostate cancer (CRPC), CPIs significantly increased intratumoral $T_{h} 1$ cells and enhanced survival of a subcutaneous model but failed to elicit a response or generate $\mathrm{T}_{\mathrm{h}} 1$ cells in a bone model. In this study, TGF- $\beta$ mediated an increase in Tregs in the TME, with an associated increase in $T_{h} 17$ cells. Combination therapy with anti-CTLA-4 plus anti-TGF- $\beta$ significantly reduced Treg and increased $T_{h} 1$ cell levels [75]. In a mouse breast cancer model, overexpression of COX2 resulted in an increase in bone metastasis and increased Treg recruitment to the tumor without accompanying myeloid-derived suppressor cells (MDSCs). Elevated levels of PGE2 in tumor cells led to the recruitment of Tregs, and blockade using an anti-PGE2 antibody or genetic suppression of COX2 expression in tumor cells reduced bone metastases [79]. In another breast cancer bone metastasis model, inhibition of the CXCL12/CXCR4 axis in combination with IDO1 expression reduced Treg levels and bone metastasis [80].

The RANK-RANKL signaling pathway is of particular interest. In bone, this pathway is involved in controlling osteoclastogenesis 
and bone resorption. Interestingly, Tregs are for producing RANKLexpressing metastatic breast cancer cells, expressing fourfold more RANKL mRNA than Tconvs; blockade of this pathway can reduce the frequency of pulmonary metastasis [81]. It is thought that the bone microenvironment generates a prometastatic niche feedback loop since both osteoclasts and Tregs produce more RANKL in the presence of tumors, which induces further bone resorption. In turn, the resulting resorption of bone lacuna by osteoclasts causes local acidification of the microenvironment to activate TGF- $\beta$, which generates more Tregs [75]. The evidence further suggests that TCR triggering of BM tumor antigen-specific Tregs, but not Tconvs, induces tumor cell egression from the BM into the peripheral blood and tumor tissue, mediated by emigration receptor S1P1 and homing receptor CCR2, providing a plausible mechanism for bone metastasis reducing systemic antitumor immunity [82]. Finally, the BM is a relatively hypoxic environment at baseline, and hypoxia has been shown to increase Treg cell number and function in a HIF1a-dependent manner and promote bone metastasis [83]. A targeted combination approach will be needed to address bone metastasis and its potential influence on systemic antitumor immunity. Indeed, the Sharma group reported that their model experiments with a therapy consisting of anti-CTLA- 4 plus anti-TGF- $\beta$ showed a significantly increased frequency of antitumor $T_{h} 1$ cells with a concomitantly decreased frequency of Tregs in bone metastasis [75]. However, the anti-RANKL antibody seems to be a more effective inhibitor of bone metastasis and has been shown to be even more effective than bisphosphates [84].

\section{TREGS IN LIVER METASTASIS}

The liver immune system is highly specialized to adapt to several notable hepatic functions. First, a significant portion of blood from the gastrointestinal tract drains via the portal vein [85]. Dietary antigenic load taken up by Peyer's patches and lamina propria enters the bloodstream via the portal vein, reaching the liver before entering the systemic circulation. As many consumed antigens are harmless, the liver is essential in preventing immune over-reactivity and contributes to antigen-specific oral tolerance [86]. As the largest internal organ in the body, the liver receives approximately $1.5 \mathrm{~L}$ of blood from the circulatory system per minute via the portal vein as well as the hepatic artery [85]. Thus, in addition to innocuous dietary and commensal gut antigens, the liver comes into contact with blood-borne bacteria, viruses, parasites, and cancer cells. The mammalian liver is also unique in its ability to regenerate following partial liver resection, which requires a well-coordinated immune cell program to maintain optimal pro- and anti-inflammatory mediators [87]. Interestingly, in mammals, the liver serves as the main multilineage hematopoietic organ during fetal development [88]. Therefore, during development, homeostasis, and injury, the liver is a multifunctional immunoregulatory organ capable of orchestrating wellcontrolled immune responses.

The complex immune functions of the liver require highly specialized adaptive and innate immune cells and have long been of interest to immunologists. Immune cell subsets within the liver have been extensively reviewed $[85,89]$. A striking feature of liver histology is the abundance of liver-resident cell types that contribute to Treg generation, including but not limited to Kupffer cells (KCs), liver sinusoidal endothelial cells (LSECs), hepatic stellate cells (HSCs), hepatocytes, and dendritic cells (DCs) [89]. Tregs are essential for hepatic tissue immune homeostasis. The depletion of Tregs during development can result in increased hepatic type 1 inflammation, autoimmune hepatitis, and subsequent metabolic disorders [26]. Several well-studied mediators are frequently highlighted in the context of Treg maintenance of immune quiescence in the liver. IL-10 is a suppressive cytokine that modulates Treg activity, and IL-10 secreted by Tregs contributes to their suppressive function [90]. For example, hepatic DCs and KCs can induce and expand Tregs through IL-10, while Tregs themselves are the predominant source of IL-10 in the gut $[26,91]$. CTLA-4 is a critical regulatory protein constitutively expressed by Tregs and is thought to be key to the critical mechanisms of Treg suppression through its competition with CD28 for CD80/86 binding or induced reduction in APC CD80/86 expression [92]. TGF- $\beta$ is abundant in the liver microenvironment and is both secreted and internalized by Tregs. LSECs, HSCs, and KCs produce TGF- $\beta$, which can facilitate the generation of liver Tregs via multiple mechanisms, including the conversion of Tconvs into Tregs [93]. Interestingly, activated liver Tregs are able to mediate systemic and extrahepatic antigen-specific tolerogenesis, a feature uniquely exploitable for autoimmune therapy purposes in non-liver diseases, such as type- 1 diabetes and multiple sclerosis [94]. Finally, emerging data suggest that certain specialized Treg mediators are adapted to liver function in gut immune homeostasis. Microbiota-derived metabolites such as short-chain fatty acids can modulate and induce Tregs, potentially through the modification of histone deacetylase activity, suggesting epigenetic regulation [95]. Fat-soluble vitamin $A$ is converted into retinoic acid (RA) by HSCs and LSECs, and RA induces guthoming receptors on Tregs and enhances their suppressive function [96]. Interestingly, the brain/CNS was recently shown to modulate Tregs through a vagal neural arc that involves the liver; specifically, the "liver-brain-gut arc" modulated Treg numbers in a colitis model. The vagal sensory afferent nerves from the liver provide signals to the brainstem and mediate feedback to the parasympathetic nerves and enteric neurons, which ultimately results in RA synthesis by colonic APCs [97].

In the metastatic cancer setting, consistent with their capabilities in tissue homeostasis, liver-derived Tregs are reportedly able to suppress both local and extrahepatic antitumor immunity. For cancers where CPIs are effective and routinely used, such as melanoma, lung cancer, urothelial and kidney cancers, we and others have shown that liver metastasis is associated with a significantly lower rate of response to immunotherapy $(<25 \%)$ and lower survival $[9,12]$. The mechanism of immunosuppression by Tregs in the context of liver metastasis is an area of active research, and much of the available knowledge has been derived from observations of primary liver cancers such as hepatocellular carcinoma (HCC), not the systemic immune impact of liver metastases. In HCC, the quantities of Tregs within the tumor and the blood are increased, and higher numbers of Tregs are often associated with worse outcomes for patients with either primary or metastatic liver tumors [98]. Histologically, there may also be a correlation between higher tumor grade and poorly differentiated liver tumors [99]. In prostate cancer liver metastasis, an association was found between increased Tregs and local IDO1 expression and the loss of the tumor suppressor gene PTEN in the patient tissue samples [49]. Phenotypically, data suggest increased activation status and potency of Tregs associated with liver tumors. For example, in metastatic colorectal cancer (mCRC) with liver metastasis, increased $\mathrm{COX}-2^{+}$Tregs have been associated with increased blood prostaglandin $E_{2}\left(P_{G} E_{2}\right)$, and they were found to correlate with decreased TNFa and IFNY on CD3 T cells and unfavorable outcomes [100]. In HCC and mCRC with liver metastases, Tregs expressed elevated levels of GITR, LAG3, ICOS, CD39, and CTLA-4 [98]. Blockade of these inhibitory surface proteins led to improved antitumor immunity, often when blocked in combination [101]. The cytokines IL-10, IL-35, and TGF- $\beta 1$ have been associated with enhanced Treg-mediated suppression of antitumor immunity in HCC [102-104]. Whole transcriptome analysis of Tregs revealed that the genes encoding layilin ( $L A Y N)$ and glucocorticoid-induced leucine zipper (TSC22D3) are upregulated in Tregs associated with liver tumors [20,105].

Finally, two recent studies investigated the mechanism of liver metastasis suppression of extrahepatic tumor immunity using a 
syngeneic immunocompetent murine tumor model. In one report, liver metastases created a systemic "immune desert" with reduced antitumor CD8 T cells via FasL-mediated clonal deletion of tumor antigen-specific $T$ cells by $C D 11 b^{+}$suppressive monocytes [21]. In contrast, $\mathrm{CD} 11 \mathrm{~b}^{+}$suppressive monocytes were also found to be abundant in extrahepatic tumors in mice bearing liver tumors, but this abundance was dependent on an associated increase in CTLA4- PD-1-, and ICOS-high Tregs. Depletion of highly activated Tregs with Treg-depleting anti-CTLA-4 antibody was able to reverse liver metastasis-mediated systemic immunosuppression [20].

\section{TREGS IN SKIN METASTASIS}

The skin, a part of the integumentary system, is considered the largest and most exposed organ in the human body [106]. With an estimated surface area of $1.8 \mathrm{~m}^{2}$ in adults and containing twice the number of $T$ cells than the circulatory system, at approximately 20 billion cells, it is a habitat for commensal organisms and, from the perspective of the immune system, in constant contact with foreign antigens and the environment [107]. Tregs, making up approximately $10 \%$ of resident T cells in the skin, is essential in regulating the complex immune interaction and homeostasis needed for defense, tolerance, and tissue repair [108]. Dysregulation of Tregs has been shown to contribute to many skin pathologies, such as psoriasis, contact dermatitis, pemphigus vulgaris, alopecia, and systemic sclerosis $[109,110]$. Animal models have shown that colonization of skin bacteria during neonatal development, but not in adulthood, can activate antigen-specific Tregs across an intact skin barrier, suggesting a window period crucial for commensal tolerance [111]. Cutaneous Tregs were found to express high levels of CD25, L-selectin, GITR, FOXP3, and intracellular CTLA-4, low levels of CD69, and high levels of the skin-homing molecules CLA, CCR4, and CCR6 [112]. The lack of homing molecules CD103, CCR4, or P- and E-selectin ligands impaired the migration and retention of Tregs within the skin and resulted in skin-specific autoimmunity [108]. Skin Tregs were found to be capable of expansion in both an antigen-specific and antigen-independent manner in response to dermal fibroblasts [112]. Depletion of Tregs was shown to result in the activation of dermal fibroblasts and activation of profibrotic gene expression in the skin, suggesting its role in fibrotic diseases [113]. The survival of skin memory Tregs was found to be dependent more heavily on IL-7 than on IL-2 [114]. The suppressive mechanism is thought to be mediated by the cytokines IL-10 and TGF- $\beta$ under some circumstances but not others $[108,112]$. A unique function of skin Tregs is their role in hair growth. Hair follicle (HF) stem cells failed to transition into the active growth phase upon Treg depletion in animal studies. Skin Tregs apparently localize next to HFs, and expression of the Notch ligand Jagged-1 (Jag1) on Tregs facilitate the proliferation of HFs [115]. This not only facilitates hair growth but also facilitates the migration of HF stem cells into a wound, where they differentiate toward keratinocytes in the context of skin injury [27].

Although the skin is susceptible to several primary sunassociated cutaneous malignancies, it is generally not a site of metastatic disease for other cancers. Metastatic cancer has been found in only $0.7-9 \%$ of cases, with lung and breast carcinomas being most the common cancers of origin [116]. Consistent with the theory that Tregs participate in a natural feedback response to $T$ cells sensitive to cancer neoantigens, melanoma metastasis that contains infiltrating activated CD8 $T$ cells has the highest expression of IDO and Tregs [117]. Similarly, activated OX40 Tregs are found within cutaneous squamous cell carcinomas and are associated with subsequent metastases [118]. More Tregs have been found in specimens taken from the head and neck than in those taken from both the trunk and extremities. The head and neck are affected most frequently by cutaneous metastasis per unit surface area. Given that skin Tregs preferentially concentrate near HFs, the authors speculated that areas of increased HF density, such as the scalp, may be more permissive to tumor growth [119]. Mechanistically, the expression of the mitochondrial enzyme arginase 2 (ARG2) was preferentially increased in Tregs in metastatic melanoma compared to other diseases, such as psoriasis. Experimentally, the overexpression of ARG2 suppressed mTOR signaling, enhancing Treg fitness, while inhibition of ARG2 decreased Treg accumulation in tissues and suppressed Treg activation [120]. In a mouse model, the increased invasive and metastatic potential of melanoma was found to be mediated by direct contact between melanoma cells and Tregs. Elevated expression of TGF- $\beta$ by Tregs induced the epithelial-tomesenchymal transition (EMT), contributing to increased lung metastasis [121]. Interestingly, the tumor-infiltrating Treg quantity in mucosal melanoma was significantly higher than that in cutaneous melanoma and was associated with a reduced response to immunotherapy, raising the possibility that despite the common presence of Tregs, the skin may not be a tissue that favors the suppression of antitumor immunity [122]

\section{TREGS IN LNS METASTASIS}

LNs are ubiquitous throughout the body and adjacent to every organ. They are part of the lymphatic system and are essential for immunosurveillance and the control of autoimmunity. They are sites of lymph drainage from all tissues, where organ-specific environments and their associated antigens are presented for lymphocyte priming. Therefore, LNs can be considered sentinel and reservoir sites that provide additional adaptive immune cell support to tissues in need of pathogenic defense [123]. However, autoimmunity can arise when dysregulated recognition of selfantigens by adaptive immune cells leads to priming and activation of $\mathrm{T}$ follicular helper cells $\left(T_{\mathrm{FH}}\right)$ and autoreactive B cells in $\mathrm{LN}$ germinal centers (GSs) [124]. Tregs are critical in LNs at steadystate and maintain a delicate balance between immunity and tolerance. Experiments with murine models have shown that LN stromal cells induce Treg activation in an IL-2-dependent manner [124]. LN-specialized $\mathrm{T}$ follicular regulatory (Tfr) cells may play a dominant role in controlling $\mathrm{T}_{\mathrm{FH}}$ and $\mathrm{B}$ cells in LNs and are characterized by higher expression of ICOS, PD-1, CXCR5, TGF- $\beta$, and PD-1 [125].

LNs are frequent sites of metastatic spread; therefore, interest in studying the roles of Tregs in LN metastases remains high. Studies of the physiological trafficking of Tregs have demonstrated that Tregs with an effector phenotype, such as CD103-expressing Tregs, are preferentially retained in LNs, compared to other CD4 T cells $[126,127]$. There is evidence that an increased number of Tregs is associated with LN metastases in multiple tumor types. In a study of 30 patients with lung adenocarcinoma, Treg levels were elevated in LNs with metastatic tumor foci involvement but not in benign LNs, suggesting a critical role for Tregs in the formation of an immunosuppressive TME [128]. Studies of breast cancer surgical specimens suggested that tumor invasion into draining LNs is associated with Treg accumulation [129]. In a recent study by Gonzalo Nunez et al., Tregs from matched tumor-invaded and noninvaded tumor-draining LNs were compared with those in primary breast tumors, and the results demonstrated that Treg frequency increased with nodal invasion. Tregs also express higher levels of coinhibitory/stimulatory receptors than effector cells [129]. In patients with colorectal cancer, a higher proportion of Tregs and other T cells with suppressive immunophenotypes were found in regional LNs, especially those nearest a tumor [130].

\section{TREGS IN THE BRAIN AND ADRENAL METASTASIS}

The brain was originally considered an "immune-privileged" organ site, initially defined through early experiments showing that the blood-brain barrier limited access to immune cells circulating in 
the peripheral immune system, an effective lymphatic system to drain the CNS was lacking, and APCs that express MHC class I and II molecules were absent [131]. However, over the past two decades, substantial progress has been made in understanding neuroimmune interactions, and the brain is currently regarded as an organ that has evolved with complex and dynamic immunoregulatory functions [132]. Due to its unique anatomic location and spatial constraints, the brain requires potent immune regulation, as an overreactive immune response can cause immediate and life-threatening CNS damage $[133,134]$. Tregs in the brain appears critical for mediating immune homeostasis and facilitating injury repair. In the brain, Tregs appear to be activated by microglial cells, which trigger the secretion of the suppressive cytokines IL-10 and IL-35 [132]. Multiple sclerosis (MS) is an autoimmune inflammatory disorder of the CNS, and Treg dysregulation and related genetic polymorphisms have been associated with MS. For example, reduced IL-10 production, genetic variations of CD25, reduced CTLA-4 and TGF- $\beta$ expression, and fewer suppressive Tregs in the CNS have been reported in patients with MS $[135,136]$. In experimental autoimmune encephalomyelitis (EAE) animal models, antigen-specific Tregs mediated the control of autoimmune pathology [137]. Regarding tissue repair, ablation of Tregs promoted the worsening of infarcts in a brain ischemia model, and transfer of IL-10-deficient Tregs was ineffective in secondary prevention of infarct growth, suggesting the importance of Treg production of IL-10 [138]. IL-33 production by stromal cells and ST2 expression on Tregs were shown to be required for Treg trafficking to injured sites in the CNS [139]. Interestingly, brain Tregs express the serotonin receptor $5-\mathrm{HT}_{7}$ and respond to neurotransmitters by upregulating suppressive and pro-repair molecules such as AREG [139].

Treatment of brain tumors and metastases without overstimulating local immunity within the brain is paramount to its safety and success $[133,134]$. In metastatic melanoma with brain metastasis, CPI is effective but has significantly lower response rates than cutaneous lesions, suggesting an influence of tissuespecific immunoregulatory factors [140]. Although the mechanisms of resistance may be different between metastatic and primary brain tumors, for the latter, CPIs have not achieved similar efficacy [141]. Tregs were found to infiltrate brain tumors in high numbers and to be increased in the blood and tumors of glioma patients and murine models, and the depletion of Tregs has been associated with improved survival [142,143]. In lung cancer patients with brain metastasis, increased Tregs were found in the peripheral blood and were associated with increases in MDSCs and IL-6 expression [143]. Wainwright et al. reported Helios ${ }^{+}$ thymus-derived natural Tregs to be the predominant type of Tregs infiltrating brain tumors [144]. The meningeal lymphatic vessels provide drainage from the CNS into the cervical LN, where brain tumor-associated Tregs are found [145]. Several groups have reported that the TGF- $\beta$ and IDO pathways are mechanistically relevant $[146,147]$. Gliomas express high levels of TGF- $\beta$, and TGF$\beta$ neutralization leads to decreases in brain tumor-infiltrating Tregs, suggesting a role for TGF- $\beta$ in modulating Tregs [148]. IDO is also elevated in glioma specimens, and its upregulation has been associated with a decrease in OS. In a model of brain tumors, IDO-competent tumors were accumulated and support Treg expansion in IDO-deficient mice, suggesting the importance of IDO as a local factor modulating Treg activity [147].

The adrenal gland is the primary site of endogenous glucocorticoid production, and given that glucocorticoids are associated with tolerogenic $\mathrm{T}$ cell activity and reduced immunotherapy response, there is a possibility that the adrenal microenvironment is uniquely immunosuppressive [149]. Tissuespecific Treg biology in the adrenal gland is not well understood; however, in the context of glucocorticoids, it has been shown that Tregs express $\beta 1$-adrenergic and glucocorticoid a receptors; therefore, these cells may be susceptible to steroid modulation
$[150,151]$. In stress models, glucocorticoid signaling has been reported to decrease systemic Treg levels or disrupt their function $[150,151]$. Given the unique function of the adrenal gland as the source of glucocorticoids and the known deleterious effects on both effector $\mathrm{T}$ cells and Tregs, more research is needed to understand the potential influence of Tregs in the adrenal gland in the context of cancer immunotherapy. Indeed, adrenal tumors are heavily infiltrated by Tregs, and a recent analysis of CPI trials with adrenal cancers revealed a generally dismal response [152]. Even for MSI-H mCRC patients where CPI is extremely effective, emerging reports indicate that the adrenal site may be a sanctuary site of resistance showing a dissociated response pattern [153].

\section{SYSTEMIC AND TISSUE-SPECIFIC TREG TARGETING FOR CANCER IMMUNOTHERAPY}

Given the importance of Tregs in promoting tumor growth and metastasis, there has been great interest in developing immunotherapies that target Tregs in cancer. The role of Tregs in antitumor immunity was initially reported in 1999 by Sakaguchi et al. [154]. In this study, the group demonstrated increased tumor rejection in mice treated with anti-CD25 antibodies, which depleted $\mathrm{CD} 4{ }^{+} \mathrm{CD} 25^{+}$Tregs in mice. Similarly, in other preclinical models, depletion of Foxp3 ${ }^{+}$Tregs was effective not only in treating tumors but also in preventing malignant formation, acting as a cancer vaccine [155].

Despite the promising preclinical results obtained over decades, the clinical application of targeted Treg therapy has been difficult as cancer immunotherapy. First, Tregs and activated effector T cells share many of the same cell surface markers, such as CD25 and CTLA-4, making it challenging to specifically deplete Tregs without affecting effector $T$ cells. Second, Tregs also play an indispensable role in preventing autoimmunity, and thus far, it has been challenging to specifically deplete tumor-directed Tregs without affecting peripheral Tregs (e.g., circulating Tregs, lymphoid-resident Tregs, and tissue-resident Tregs) to prevent autoimmune side effects. To overcome these issues and achieve greater specific antibody-mediated killing of tumor Tregs, one approach is to better target surface molecules that are expressed or are elevated only on intratumor Tregs, such as CD25, CTLA-4, GIRT, 4-1BB, OX-40, LAG3, TIGHT, CCR4, and CCR8 [156]. Antibodydependent Treg cell depletion can exploit differences between tumor Treg and effector T cell kinetics and targets. While there are many similarities in the cell surface markers expressed on Tregs vs. effector T cells, there are differences in the expression levels and kinetics currently being studied, which can be exploited. For example, an anti-CTLA-4 monoclonal antibody within the lgG2a subclass depleted Tregs specifically in tumor tissue and thus enhanced antitumor immunity [157]. Tregs constitutively express CTLA-4, but conventional T cells express only CTLA-4 when they are activated, and conventional $T$ cells express it at much lower levels than Tregs; thus, it is possible to engineer antibodies with Fc regions specifically designed to deplete Tregs without significantly reducing the effector $T$ cell population [158]. An anti-CCR4 monoclonal antibody with high antibody-dependent cellmediated cytotoxicity (ADCC) was used to deplete Tregs and enhance antitumor responses [159]. Similarly, monoclonal antibodies against CD25, OX-40, and GITR enhanced ADCC-mediated Treg depletion and slowed tumor growth [160-162]. Thus, when tissue-specific modulation is taken into account in greater detail, surface proteins expressed at high levels on intratumor Tregs can be targets of greater tumor Treg depletion by ADCC monoclonal antibodies.

In addition to exploiting differences in intratumor Treg surface protein kinetics, the specificity of Treg deletion can be confined to tumor tissue using other novel approaches. Several techniques have been employed to generate local Treg depletion. First, local intratumoral injection of anti-CTLA-4 antibody $[163,164]$ or anti- 
GIRT mAb [165], not systemic delivery, has led to decreases in tumor size while inducing tumor regression at distant sites with few systemic effects. Another technique involves the use of an antibody conjugated with a photoactivatable dye to induce lethal damage to the cell membrane of the target cells upon nearinfrared (NIR) light exposure. Using a mouse model, Sato et al. demonstrated that an anti-CD25 mAb conjugated to a photoactivatable dye deleted only tumor-localized Tregs upon exposing just the tumor to NIR light [166]. Chimeric antigen receptor (CAR) T cells engineered to deliver cytokines such as IL-12 specifically to the TME, termed "armored CARs," showed antitumor efficacy that included resistance to Treg suppression at the tumor site [167]. Finally, a promising strategy involves blocking the migration of Tregs to the TME. In a melanoma study, CCR4 was required for the homing Tregs to nascent tumor sites from LNs, and BRAF ${ }^{\mathrm{V} 600 \mathrm{E}}$ signaling controlled the expression of CCR4 chemokines, raising the possibility that inhibiting this signaling with BRAF inhibitors may have reduced Treg recruitment to the tumor [168]. In patients with cutaneous $T$ cell lymphoma, mogamulizumab, a defucosylated anti-CCR4 antibody, reduced the levels of CCR4 ${ }^{+}$Tregs and showed significant efficacy [169]. Thus, this site-specific antibody activation, migration, and cellular delivery strategies enable the depletion of intratumoral Tregs or suppression of their immunesuppressing activity with a diminished effect on peripheral Tregs, potentially allowing improved therapeutic efficacy with distinct cancer immune responses without the induction of autoimmunity.

Another emerging area of interest is combining locoregional metastatic-site interventions with CPIs to induce an augmented response. Although the abscopal effect, or treatment response at a tumor site that was not the direct target of local therapy, has been sporadically reported, these effects have not been widely studied in the era of modern immunotherapy or with improved technology, which enables an analysis of tissue-specific regulatory mechanisms in detail. Locoregional cancer treatment therapies, including radiotherapy and surgery, combined with CPIs, are readily available and rational approaches for removing tumors and reducing tissue-resident suppressors such as Tregs to tip the immune balance toward antitumor immunity, potentiating the abscopal effect. Although clinical data on surgical metastasectomies in combination with CPIs are not yet available, experimental models have shown that surgical removal of metastatic tumors can eliminate immunosuppressive elements and is a powerful local force that disrupts the tumor-immune ecosystem [170]. However, the subsequent redistribution of immune cells following surgery may swing immunosuppressive responses in cancer patients in either direction. Surgical trauma and wound healing responses following surgery can counterbalance the potential benefits of surgery. Krall et al. [171] developed a mouse model that showed that activation of wound repair mechanisms induced by surgical incisions resulted in diminished local and systemic antitumor immunity. Finally, laparotomy in preclinical models has been shown to induce CCL18 expression within the peritoneal cavity and promote Treg recruitment [172]. Thus, while randomized trials are ongoing to examine whether surgeries such as palliative nephrectomies may benefit therapeutic antitumor immunity (NCT03977571), there is a conceptual concern that surgery-related immunosuppression may limit this approach [173].

Radiotherapy is a noninvasive locoregional treatment modality. While palliative fractionated radiation has historically been used only for symptom palliation in metastatic cancer patients, there is emerging random evidence indicating that consolidation of disease in oligometastatic patients with focal stereotactic ablative body radiation may improve the progression-free and OS of patients [174]. Data obtained to determine whether radiotherapy alters Tregs are controversial. Chemoradiation has been shown to increase Tregs in head and neck cancer patients [175] but has also been shown to decrease Tregs in rectal cancer and cervical cancer patients [176] and pancreatic cancer patients [177]. Thus, it is not yet fully understood whether ablative consolidation with radiotherapy alters Tregs to enhance therapeutic antitumor immunity in patients, and additional understanding of tissue-specific immunology and the clinical correlation is required.

In preclinical models, it has been shown that fractionated largefield or whole-body radiotherapy actually increases the number of systemic Tregs [178]. In multiple preclinical models, radiation can cause lymphopenia, which can promote relative expansion in Treg cell numbers because they are more radioresistant than other lymphocytes [179]. Preclinical evaluation of the impact of radiation on Tregs has indicated that the dose and degree of fractionation matter and can lead to diverse immune responses. Ablative hypofractionated and fractionated radiation reduces Treg numbers in MC38 models [180]. This finding has also been observed in LM8 osteosarcoma models [181]. Mechanistically, radiotherapy has been shown to diminish tumoral CCL22, resulting in a diminished number of Tregs [182]. In contrast, subablative doses of radiation increased the number of intratumoral Tregs in multiple models [183]. Although radiation can induce TGF- $\beta$ expression, which pleiotropically promotes Tregs [184,185], radiotherapy can also induce Treg expression in TGF- $\beta$-independent pathways [186]. In terms of the abscopal effect, there are emerging preclinical data suggesting that radiotherapy may promote systemic antitumor immune responses and promote tumor rejection of unirradiated tumors $[187,188]$. However, currently, evidence showing that radiotherapy promotes systemic antitumoral immune responses in unirradiated tumors in patients is limited [189]. Hence, there is significant interest in developing combinatorial strategies to enhance systemic antitumor immune responses that involve Tregs. Depletion of Tregs using genetic approaches promotes antitumor immunity following irradiation of preclinical models of mesothelioma [190]. Similarly, GITR agonizts and PI3Ka $\delta$ inhibitors that deplete Treg numbers promoted the antitumor efficacy of radiation exposure in multiple models $[191,192]$. Finally, inhibition of TGF- $\beta$ in concert with radiotherapy at low doses can modulate antitumor immune responses and may diminish the effect of Tregs in patients [185]. Collectively, these data suggest that the degree to which radiation exposure modulates Tregs depends on the context and intensity of the therapy, which may depend on tissue-specific factors. Future studies will provide clinical and mechanistic insights into how to precisely combine radiotherapy with immunotherapy to enhance overall antitumor immunity.

\section{CONCLUSION}

Cancer immunotherapy drugs such as CPIs provided the first proof-of-principle suggesting that we can modulate antitumor immunity to cure metastatic cancer. However, most patients do not respond to CPIs, and there is substantial variability in efficacy across tissue sites, which is observed not only in primary tumors but also at metastatic sites. To extend the benefit of these drugs to include more than a minority of cancer patients, a more complete understanding of tissue-specific Tregs is needed. Over the past several decades, in addition to their roles in cancer, Tregs have been studied as critical regulators of the immune response in tissue repair, peripheral tolerance, allergy, inflammation, and interactions with the commensal microbiome [193]. However, despite our current knowledge, the successful therapeutic manipulation of Tregs has been difficult. There is growing consensus that to overcome the remaining challenges, we must reconcile the variability of the responses distinct to cancer types and organ metastasis with the specialized, tissue-adapted mechanisms of Treg immunoregulation. The observation that not all tissue sites respond equally to immunomodulating drugs coupled with recent advances revealing numerous tissue-specific adaptations of Tregs, suggests that tissue-specific targeting of Tregs may be necessary to overcome their regulatory control. Environmental inputs affecting Tregs, such as oxygen tension 
changes in the lungs, tissue regeneration in the liver, changes in the gut microbiome, bone turnover, and even neuronal signals in the CNS, can have profound context-specific effects on tissueresident Tregs and impact tumor immunity. In addition, since Tregs are essential for maintaining immune homeostasis, safe and effective immunotherapy will require more precise targeting of Tregs, not complete systemic deletion. Insights into specialized Tregs suggest that this specific targeting be achieved by exploiting differences in cell surface receptors, genetic programming, the kinetics of protein expression, and other context-specific local mediators (Fig. 2). To enhance both the efficacy and safety of combined precision immunotherapy, treatments can be tailored to specific primary or metastatic sites with locoregional interventional approaches or with drugs designed to be deleterious to tissue-specific Tregs by targeting pathways most critical to the relevant Treg biology. Decades of research on Tregs point to their critical importance on the roadmap to a cure for metastatic cancer and have paved the way for the future of precision cancer immunotherapy.

\section{REFERENCES}

1. Ehrlich P. Address in pathology, ON CHEMIOTHERAPY: delivered before the Seventeenth International Congress of Medicine. Br Med J. 1913;2:353-9.

2. Coley WB. The treatment of inoperable sarcoma with the'mixed toxins of erysipelas and bacillus prodigiosus.: immediate and final results in one hundred and forty cases. J Am Med Assoc. 1898;XXXI:456-65.

3. Zhang $Y$, Zhang Z. The history and advances in cancer immunotherapy: understanding the characteristics of tumor-infiltrating immune cells and their therapeutic implications. Cell Mol Immunol. 2020;17:807-21.

4. McFarland CD, Mirny LA, Korolev KS. Tug-of-war between driver and passenger mutations in cancer and other adaptive processes. Proc Natl Acad Sci USA. 2014;111:15138-43.

5. Schumacher TN, Schreiber RD. Neoantigens in cancer immunotherapy. Science 2015;348:69-74.

6. Larkin J, Chiarion-Sileni V, Gonzalez R, Grob J-J, Rutkowski P, Lao CD, et al. Fiveyear survival with combined nivolumab and ipilimumab in advanced melanoma. N Engl J Med. 2019;381:1535-46.

7. Overman MJ, Lonardi S, Wong KYM, Lenz HJ, Gelsomino F, Aglietta M, et al. Durable clinical benefit with nivolumab plus ipilimumab in DNA mismatch repair-deficient/microsatellite instability-high metastatic colorectal cancer. J Clin Oncol. 2018;36:773-9.

8. Haslam A, Prasad V. Estimation of the percentage of us patients with cancer who are eligible for and respond to checkpoint inhibitor immunotherapy drugs. JAMA Netw Open 2019. https://doi.org/10.1001/jamanetworkopen.2019.2535.

9. Tumeh PC, Hellmann MD, Hamid O, Tsai KK, Loo KL, Gubens MA, et al. Liver metastasis and treatment outcome with Anti-PD-1 monoclonal antibody in patients with melanoma and NSCLC. Cancer Immunol. Res. 2017;5:417-24.

10. Pires Da Silva IED, Lo S, Gonzalez M, Guminski A, Long GV, Menzies AM. Distinct patterns of response and toxicity (tox) by sites of metastases (mets) in patients (pts) treated with ipilimumab combined with PD-1 antibodies (ipi+PD1). J Clin Oncol. 2018. https://doi.org/10.1200/jco.2018.36.15_suppl.9553.

11. Bilen MA, Shabto JM, Martini DJ, Liu Y, Lewis C, Collins $H$, et al. Sites of metastasis and association with clinical outcome in advanced stage cancer patients treated with immunotherapy. BMC Cancer. 2019;19:1-8.

12. Topalian SL, Hodi FS, Brahmer JR, Gettinger SN, Smith DC, McDermott DF et al. Five-year survival and correlates among patients with advanced melanoma, renal cell carcinoma, or non-small cell lung cancer treated with nivolumab. JAMA Oncol. 2019. https://doi.org/10.1001/jamaoncol.2019.2187.

13. Hellmann MD, Ciuleanu T-E, Pluzanski A, Lee JS, Otterson GA, Audigier-Valette $C$ et al. Nivolumab plus ipilimumab in lung cancer with a high tumor mutational burden. N Engl J Med. 2018. https://doi.org/10.1056/NEJMoa1801946 .

14. McGrail DJ, Pilié PG, Rashid NU, Voorwerk L, Slagter M, Kok M, et al. High tumor mutation burden fails to predict immune checkpoint blockade response across all cancer types. Ann Oncol. 2021;32:661-72.

15. Pires da Silva I, Lo S, Quek C, Gonzalez M, Carlino MS, Long GV et al. Site-specific response patterns, pseudoprogression, and acquired resistance in patients with melanoma treated with ipilimumab combined with anti-PD-1 therapy. Cancer 2020. https://doi.org/10.1002/cncr.32522.

16. Esfahani K, Elkrief A, Calabrese C, Lapointe R, Hudson M, Routy B, et al. Moving towards personalized treatments of immune-related adverse events. Nat Rev Clin Oncol. 2020;17:504-15.
17. Kang $\mathrm{J}$, Bluestone $J A$, Young A. Predicting and preventing immune checkpoint inhibitor toxicity: targeting cytokines. Trends Immunol. 2021;42:293-311.

18. Young A, Quandt Z, Bluestone JA. The balancing act between cancer immunity and autoimmunity in response to immunotherapy. Cancer Immunol Res. 2018;6:1445-52.

19. Oliver AJ, Keam SP, von Scheidt B, Zanker DJ, Harrison AJ, Tantalo DGM et al. Primary and metastatic breast tumors cross-talk to influence immunotherapy responses. Oncolmmunology 2020. https://doi.org/10.1080/2162402X.2020.1802979.

20. Lee, J, Mehdizadeh, S, Smith, J, Young, A, Mufazalov, I, Mowery, C, Daud, A, Bluestone J. Regulatory T cell control of systemic immunity and immunotherapy response in liver metastasis. Sci Immunol. 2020;5.

21. Yu J, Green MD, Li S, Sun Y, Journey SN, Choi JE, et al. Liver metastasis restrains immunotherapy efficacy via macrophage-mediated T cell elimination. Nat Med. 2021. https://doi.org/10.1038/s41591-020-1131-x.

22. Sharma P, Hu-Lieskovan S, Wargo JA, Ribas A. Primary, adaptive, and acquired resistance to cancer immunotherapy. Cell 2017. https://doi.org/10.1016/j. cell.2017.01.017.

23. Berendt MJ, North RJ. T-cell-mediated suppression of anti-tumor immunity. An explanation for progressive growth of an immunogenic tumor. J. Exp. Med. 1980;151:69-80.

24. Sakaguchi S, Mikami N, Wing JB, Tanaka A, Ichiyama K, Ohkura N. Annual review of immunology regulatory $T$ cells and human disease. 2020. https://doi.org/ 10.1146/annurev-immunol-042718.

25. Cooper MD, Alder MN. The evolution of adaptive immune systems. Cell 2006;124:815-22.

26. Campbell C, Rudensky A. Roles of regulatory T cells in tissue pathophysiology and metabolism. Cell Metab. 2020;31:18-25.

27. Mathur AN, Zirak B, Boothby IC, Tan M, Cohen JN, Mauro TM, et al. Treg-cell control of a CXCL5-IL-17 inflammatory axis promotes hair-follicle-stem-cell differentiation during skin-barrier repair. Immunity. 2019;50:655-667.e4.

28. Nosbaum A, Prevel N, Truong H-A, Mehta P, Ettinger M, Scharschmidt TC, et al. Cutting edge: regulatory $T$ cells facilitate cutaneous wound healing. J Immunol. 2016;196:2010-4.

29. Haertel E, Joshi N, Hiebert P, Kopf M, Werner S. Regulatory T cells are required for normal and activin-promoted wound repair in mice. Eur J Immunol. 2018;48:1001-13.

30. Arpaia N, Green JA, Moltedo B, Arvey A, Hemmers S, Yuan S, et al. A distinct function of regulatory T. Cells Tissue Prot Cell. 2015;162:1078-89.

31. Zaiss DMW, Gause WC, Osborne LC, Artis D. Emerging functions of amphiregulin in orchestrating immunity, inflammation, and tissue repair. Immunity. 2015;42:216-26.

32. Worster DT, Schmelzle T, Solimini NL, Lightcap ES, Millard B, Mills GB, et al. Akt and ERK control the proliferative response of mammary epithelial cells to the growth factors IGF-1 and EGF through the cell cycle inhibitor p57Kip2. Sci. Signal. 2012;5:ra19-ra19.

33. Minutti CM, Modak RV, Macdonald F. A macrophage-pericyte axis directs tissue restoration via amphiregulin-induced transforming growth factor beta activation. Immunity. 2019;50:645-54.

34. Serezani APM, Bozdogan G, Sehra S, Walsh D, Krishnamurthy P, Sierra Potchanant $E A$, et al. IL-4 impairs wound healing potential in the skin by repressing fibronectin expression. J Allergy Clin Immunol. 2017;139:142-151.e5.

35. Burzyn D, Kuswanto W, Kolodin D, Shadrach JL, Cerletti M, Jang Y. et al. A special population of regulatory $\mathrm{T}$ cells potentiates muscle repair. Cell. 2013;155:1282-95.

36. Weirather Johannes Hofmann, Ulrich DW, Niklas Beyersdorf, Gustavo Ramos $C$ Benjamin Vogel, Frey Anna. et al. Foxp3+ CD4+ T cells improve healing after myocardial infarction by modulating monocyte/macrophage differentiation. Circ Res. 2014;115:55-67.

37. Deyell M, Garris CS, Laughney AM. Cancer metastasis as a non-healing wound. Br J Cancer 2021. https://doi.org/10.1038/s41416-021-01309-w.

38. Togashi $Y$, Shitara K, Nishikawa H. Regulatory T cells in cancer immunosuppression-implications for anticancer therapy. Nat Rev Clin Oncol. 2019;16:356-71.

39. Tang Y, Xu X, Guo S, Zhang C, Tang Y, Tian Y, et al. An increased abundance of tumor-infiltrating regulatory $T$ cells is correlated with the progression and prognosis of pancreatic ductal adenocarcinoma. PloS ONE. 2014;9:e91551.

40. Tao H, Mimura Y, Aoe K, Kobayashi S, Yamamoto H, Matsuda E, et al. Prognostic potential of FOXP3 expression in non-small cell lung cancer cells combined with tumor-infiltrating regulatory $T$ cells. Lung Cancer. 2012;75:95-101.

41. Curiel TJ, Coukos G, Zou L, Alvarez X, Cheng P, Mottram P, et al. Specific recruitment of regulatory $T$ cells in ovarian carcinoma fosters immune privilege and predicts reduced survival. Nat Med. 2004;10:942-9.

42. Leffers N, Gooden MJM, de Jong RA, Hoogeboom B-N, ten Hoor KA, Hollema $\mathrm{H}$, et al. Prognostic significance of tumor-infiltrating T-lymphocytes in primary and 
metastatic lesions of advanced stage ovarian cancer. Cancer Immunol Immunother. 2009;58:449-59.

43. Sayour EJ, McLendon P, McLendon R, De Leon G, Reynolds R, Kresak J, et al. Increased proportion of FoxP3 + regulatory $\mathrm{T}$ cells in tumor infiltrating lymphocytes is associated with tumor recurrence and reduced survival in patients with glioblastoma. Cancer Immunol Immunother. 2015;64:419-27.

44. Yang Z-Z, Novak AJ, Stenson MJ, Witzig TE, Ansell SM. Intratumoral CD4+CD25+ regulatory T-cell-mediated suppression of infiltrating CD4+ T cells in B-cell nonHodgkin lymphoma. Blood. 2006;107:3639-46.

45. Vignali DAA, Collison LW, Workman CJ. How regulatory T cells work. Nat. Rev. Immunol. 2008;8:523-32.

46. Kryczek I, Wei S, Zou L, Zhu G, Mottram P, Xu H, et al. Cutting edge: induction of B7-H4 on APCs through IL-10: novel suppressive mode for regulatory T cells. J. Immunol. 2006;177:40-44.

47. Halvorsen EC, Mahmoud SM, Bennewith KL. Emerging roles of regulatory T cells in tumour progression and metastasis. Cancer Metastasis Rev. 2014;33:1025-41.

48. Lai $C$, August $S$, Albibas $A$, Behar $R$, Cho $S-Y$, Polak ME, et al. OX40+ regulatory $T$ cells in cutaneous squamous cell carcinoma suppress effector T-cell responses and associate with metastatic potential. Clin Cancer Res. 2016;22:4236-48.

49. Vidotto T, Saggioro FP, Jamaspishvili T, Chesca DL, Picanço de Albuquerque CG, Reis RB, et al. PTEN-deficient prostate cancer is associated with an immunosuppressive tumor microenvironment mediated by increased expression of IDO1 and infiltrating FoxP3+ T regulatory cells. Prostate. 2019;79:969-79.

50. Chen SL, Cai ZSR. Expression of CD4+CD25+ regulatory T cells and Foxp3 in peripheral blood of patients with gastric carcinoma. J Biol Regul Homeost Agents. 2016;30:197-204.

51. Holt PG, Strickland DH, Wikström ME, Jahnsen FL. Regulation of immunological homeostasis in the respiratory tract. Nat Rev Immunol. 2008;8:142-52.

52. Mock JR, Dial CF, Tune MK, Norton DL, Martin JR, Gomez JC et al. Transcriptional analysis of Foxp3+ Tregs and functions of two identified molecules during resolution of ALI. JCI Insight 2019. https://doi.org/10.1172/jci.insight.124958.

53. Morita H, Arae K, Unno H, Miyauchi K, Toyama S, Nambu A et al. An interleukin33-mast cell-interleukin-2 axis suppresses papain-induced allergic inflammation by promoting regulatory T cell numbers. Immunity 2015. https://doi.org/ 10.1016/j.immuni.2015.06.021.

54. Arpaia N, Green JA, Moltedo B, Arvey A, Hemmers S, Yuan S et al. A distinct function of regulatory T cells in tissue protection. Cell 2015. https://doi.org/ 10.1016/j.cell.2015.08.021.

55. Lu LC, Hsu C, Shao YY, Chao Y, Yen CJ, Shih IL, et al. Differential organ-specific tumor response to immune checkpoint inhibitors in hepatocellular carcinoma. Liver Cancer. 2019;8:480-90.

56. Marshall EA, Ng KW, Kung SHY, Conway EM, Martinez VD, Halvorsen EC et al. Emerging roles of $\mathrm{T}$ helper 17 and regulatory $\mathrm{T}$ cells in lung cancer progression and metastasis. Mol Cancer 2016. https://doi.org/10.1186/s12943-016-0551-1.

57. Francisco LM, Salinas VH, Brown KE, Vanguri VK, Freeman GJ, Kuchroo VK, et al. PD-L1 regulates the development, maintenance, and function of induced regulatory T cells. J Exp Med. 2009;206:3015-29.

58. He J, Hu Y, Hu M, Li B. Development of PD-1/PD-L1 pathway in tumor immune microenvironment and treatment for non-small cell lung cancer. Sci Rep. 2015;5:13110.

59. Granville CA, Memmott RM, Balogh A, Mariotti J, Kawabata S, Han W, et al. A central role for Foxp3+ regulatory $\mathrm{T}$ cells in K-Ras-driven lung tumorigenesis. PloS ONE. 2009;4:e5061.

60. Ganesan A-P, Johansson M, Ruffell B, Yagui-Beltrán A, Beltran A, Lau J, et al. Tumor-infiltrating regulatory $T$ cells inhibit endogenous cytotoxic $T$ cell responses to lung adenocarcinoma. J Immunol. 2013;191:2009-17.

61. Wang W, Hodkinson P, McLaren F, MacKinnon A, Wallace W, Howie S, et al. Small cell lung cancer tumour cells induce regulatory $T$ lymphocytes, and patient survival correlates negatively with FOXP3+ cells in tumour infiltrate. Int J Cancer. 2012;131:E928-937.

62. Erfani N, Mehrabadi SM, Ghayumi MA, Haghshenas MR, Mojtahedi Z, Ghaderi A, et al. Increase of regulatory $T$ cells in metastatic stage and CTLA-4 over expression in lymphocytes of patients with non-small cell lung cancer (NSCLC). Lung Cancer. 2012;77:306-11.

63. Clever D, Roychoudhuri R, Constantinides MG, Askenase MH, Sukumar M, Klebanoff $C A$, et al. Oxygen Sensing by $T$ cells establishes immunologically tolerance metastatic niche. Cell. 2016;166:1117-1131.e14.

64. Shimizu K, Nakata M, Hirami Y, Yukawa T, Maeda A, Tanemoto K. Tumorinfiltrating Foxp3+ regulatory $\mathrm{T}$ cells are correlated with cyclooxygenase-2 expression and are associated with recurrence in resected non-small cell lung cancer. J Thorac Oncol. 2010;5:585-90.

65. Petersen RP, Campa MJ, Sperlazza J, Conlon D, Joshi M-B, Harpole DH, et al. Tumor infiltrating Foxp3+ regulatory T-cells are associated with recurrence in pathologic stage I NSCLC patients. Cancer. 2006;107:2866-72.
66. Duan M-C, Zhong X-N, Liu G-N, Wei J-R. The Treg/Th17 paradigm in lung cancer. J Immunol Res. 2014;2014:730380.

67. Li S, Li Y, Qu X, Liu X, Liang J. Detection and significance of TregFoxP3(+) and Th17 cells in peripheral blood of non-small cell lung cancer patients. Arch Med Sci. 2014;10:232-9.

68. Yang G, Li H, Yao Y, Xu F, Bao Z, Zhou J. Treg/Th17 imbalance in malignant pleural effusion partially predicts poor prognosis. Oncol Rep. 2015;33:478-84.

69. Chen $F$, Han Y, Kang Y. Bone marrow niches in the regulation of bone metastasis. Br J Cancer 2021;124:1912-1920.

70. DiSibio G, French SW. Metastatic patterns of cancers. Arch Pathol Lab Med. 2008;132:931-9.

71. Peters S, Cappuzzo F, Horn L, Paz-Ares L, Borghaei H, Barlesi F, et al. OA03.05 Analysis of early survival in patients with advanced non-squamous NSCLC treated with nivolumab vs docetaxel in CheckMate 057. J Thorac Oncol. 2017;12: S253.

72. Halabi S, Kelly WK, Ma H, Zhou H, Solomon NC, Fizazi K et al. Meta-analysis evaluating the impact of site of metastasis on overall survival in men with castration-resistant prostate cancer. J Clin Oncol. 2016. https://doi.org/10.1200/ JCO.2015.65.7270.

73. Fay EK, Graff JN. Immunotherapy in prostate cancer. Cancers 2020. https://doi. org/10.3390/cancers12071752.

74. Emens LA. Breast cancer immunotherapy: facts and hopes. Clin Cancer Res. 2018;24:511-20.

75. Jiao S, Subudhi SK, Aparicio A, Ge Z, Guan B, Miura Y, et al. Differences in tumor microenvironment dictate $T$ helper lineage polarization and response to immune checkpoint therapy. Cell. 2019;179:1177-1190.e13.

76. Hirata Y, Furuhashi K, Ishii H, Li HW, Pinho S, Ding L, et al. CD150 high bone marrow Tregs maintain hematopoietic stem cell quiescence and immune privilege via adenosine. Cell Stem Cell. 2018;22:445-453.e5.

77. Fujisaki J, Wu J, Carlson AL, Silberstein L, Putheti P, Larocca R, et al. In vivo imaging of $\mathrm{T}$ reg cells providing immune privilege to the haematopoietic stemcell niche. Nature. 2011;474:216-20.

78. Zhao E, Wang L, Dai J, Kryczek I, Wei S, Vatan L, et al. Regulatory T cells in the bone marrow microenvironment in patients with prostate cancer. Oncolmmunology. 2012;1:152-61.

79. Karavitis J, Hix LM, Shi YH, Schultz RF, Khazaie K, Zhang M. Regulation of COX2 expression in mouse mammary tumor cells controls bone metastasis and PGE2induction of regulatory T cell migration. PLoS ONE. 2012;7:1-11.

80. Zhang J, Pang Y, Xie T, Zhu L. CXCR4 antagonism in combination with IDO1 inhibition weakens immune suppression and inhibits tumor growth in mouse breast cancer bone metastases. OncoTargets Ther. 2019;12:4985-92.

81. Tan W, Zhang W, Strasner A, Grivennikov S, Cheng JQ, Hoffman RM, et al. Tumour-infiltrating regulatory $\mathrm{T}$ cells stimulate mammary cancer metastasis through RANKL-RANK signalling. Nature. 2011;470:548-53.

82. Rathinasamy A, Domschke C, Ge Y, Böhm HH, Dettling S, Jansen D, et al. Tumor specific regulatory $T$ cells in the bone marrow of breast cancer patients selectively upregulate the emigration receptor S1P1. Cancer Immunol Immunother. 2017;66:593-603.

83. Clambey ET, McNamee EN, Westrich JA, Glover LE, Campbell EL, Jedlicka P et al. Hypoxia-inducible factor-1 alpha-dependent induction of FoxP3 drives regulatory T-cell abundance and function during inflammatory hypoxia of the mucosa. Proc Natl Acad Sci USA 2012. https://doi.org/10.1073/pnas.1202366109.

84. Fizazi K, Lipton A, Mariette X, Body JJ, Rahim Y, Gralow JR et al. Randomized phase II trial of denosumab in patients with bone metastases from prostate cancer, breast cancer, or other neoplasms after intravenous bisphosphonates. J Clin Oncol. 2009. https://doi.org/10.1200/JCO.2008.19.2146.

85. Doherty DG. Immunity, tolerance and autoimmunity in the liver: a comprehensive review. J Autoimmun. 2016;66:60-75.

86. Li W, Chou ST, Wang C, Kuhr CS, Perkins JD. Role of the liver in peripheral tolerance: induction through oral antigen feeding. Am J Transpl. 2004;4:1574-82.

87. Markose D, Kirkland $P$, Ramachandran $P$, Henderson NC. Immune cell regulation of liver regeneration and repair. J Immunol Regen Med. 2018;2:1-10.

88. Hadland B, Yoshimoto M. Many layers of embryonic hematopoiesis: new insights into B-cell ontogeny and the origin of hematopoietic stem cells. Exp Hematol. 2018;60:1-9.

89. Thomson AW, Knolle PA. Antigen-presenting cell function in the tolerogenic liver environment. Nat Rev Immunol. 2010;10:753-66.

90. Rubtsov YP, Rasmussen JP, Chi EY, Fontenot J, Castelli L, Ye X et al. Regulatory T cell-derived interleukin-10 limits inflammation at environmental interfaces. Immunity 2008. https://doi.org/10.1016/j.immuni.2008.02.017.

91. Heymann F, Peusquens J, Ludwig-Portugall I, Kohlhepp M, Ergen C, Niemietz P et al. Liver Inflammation Abrogates Immunological tolerance induced by Kupffer cells. Hepatology 2015. https://doi.org/10.1002/hep.27793. 
92. Qureshi OS, Zheng Y, Nakamura K, Attridge K, Manzotti C, Schmidt EM et al. Trans-endocytosis of CD80 and CD86: a molecular basis for the cell-extrinsic function of CTLA-4. Science 2011. https://doi.org/10.1126/science.1202947.

93. Carambia A, Freund B, Schwinge D, Heine M, Laschtowitz A, Huber S, et al. TGF$\beta$-dependent induction of CD4+CD25+Foxp3 + Tregs by liver sinusoidal endothelial cells. J Hepatol. 2014;61:594-9.

94. Umeshappa CS, Mbongue J, Singha S, Mohapatra S, Yamanouchi J, Lee JA, et al. Ubiquitous antigen-specific $T$ regulatory type 1 cells variably suppress hepatic and extrahepatic autoimmunity. J Clin Investig. 2020;130:1823-9.

95. Arpaia N, Campbell C, Fan X, Dikiy S, Van Der Veeken J, Deroos P et al. Metabolites produced by commensal bacteria promote peripheral regulatory $\mathrm{T}$-cell generation. Nature 2013. https://doi.org/10.1038/nature12726.

96. Menning A, Loddenkemper C, Westendorf AM, Szilagyi B, Buer J, Siewert C et al. Retinoic acid-induced gut tropism improves the protective capacity of Treg in acute but not in chronic gut inflammation. Eur J Immunol. 2010. https://doi.org/ 10.1002/eji.200939938.

97. Teratani T, Mikami $Y$, Nakamoto N, Suzuki T, Harada $Y$, Okabayashi $K$, et al. The liver-brain-gut neural arc maintains the Treg cell niche in the gut. Nature. 2020;585:591-6.

98. Pedroza-Gonzalez A, Verhoef C, ljzermans JNM, Peppelenbosch MP, Kwekkeboom J, Verheij J, et al. Activated tumor-infiltrating CD4+ regulatory T cells restrain antitumor immunity in patients with primary or metastatic liver cancer. Hepatology. 2013;57:183-94.

99. Mathai AM, Kapadia MJ, Alexander J, Kernochan LE, Swanson PE, Yeh MM. Role of Foxp3-positive tumor-infiltrating lymphocytes in the histologic features and clinical outcomes of hepatocellular carcinoma. Am J Surg Pathol. 2012;36:980-6.

100. Brudvik KW, Henjum K, Aandahl EM, Bjørnbeth BA, Taskén K. Regulatory T-cellmediated inhibition of antitumor immune responses is associated with clinical outcome in patients with liver metastasis from colorectal cancer. Cancer Immunol Immunother. 2012;61:1045-53.

101. Pedroza-Gonzalez A, Zhou G, Singh SP, Boor PP, Pan Q, Grunhagen D, et al. GITR engagement in combination with CTLA-4 blockade completely abrogates immunosuppression mediated by human liver tumor-derived regulatory $T$ cells ex vivo. Oncoimmunology. 2015;4:e1051297.

102. Shi C, Chen Y, Chen Y, Yang Y, Bing W, Qi J. CD4(+) CD25(+) regulatory T cells promote hepatocellular carcinoma invasion via TGF- $\beta 1$-induced epithelialmesenchymal transition. OncoTargets Ther. 2019;12:279-89.

103. Liu X, Ren H, Guo H, Wang W, Zhao N. Interleukin-35 has a tumor-promoting role in hepatocellular carcinoma. Clin Exp Immunol. 2021;203:219-29.

104. Zhang S, Gan X, Qiu J, Ju Z, Gao J, Zhou J, et al. IL-10 derived from Hepatocarcinoma cells improves human induced regulatory T cells function via JAK1/ STAT5 pathway in tumor microenvironment. Mol Immunol. 2021;133:163-72.

105. Zheng C, Zheng L, Yoo JK, Guo H, Zhang Y, Guo X et al. Landscape of infiltrating T cells in liver cancer revealed by single-cell sequencing. Cell 2017. https://doi. org/10.1016/j.cell.2017.05.035.

106. Nguyen AV, Soulika AM. The dynamics of the skin's immune system. Int J Mol Sci. 2019;20:1-53.

107. Clark RA. Skin-resident T cells: the ups and downs of on site immunity. J Investig Dermatol. 2010;130:362-70.

108. Di Meglio P, Perera GK, Nestle FO. The multitasking organ: recent insights into skin immune function. Immunity. 2011;35:857-69.

109. Nussbaum L, Chen YL, Ogg GS Role of regulatory T cells in psoriasis pathogenesis and treatment. Br J Dermatol. 2021. https://doi.org/10.1111/bjd.19380.

110. Ujiie $\mathrm{H}$ Regulatory $\mathrm{T}$ cells in autoimmune skin diseases. Exp Dermatol. 2019 https://doi.org/10.1111/exd.13535.

111. Scharschmidt TC, Vasquez KS, Truong HA, Gearty SV, Pauli ML, Nosbaum A, et al. A wave of regulatory $T$ cells into neonatal skin mediates tolerance to commensal microbes. Immunity. 2015;43:1011-21.

112. Clark RA, Kupper TS IL-15 and dermal fibroblasts induce proliferation of natural regulatory T cells isolated from human skin. Blood 2007. https://doi.org/10.1182/ blood-2006-02-002873.

113. Kalekar LA, Cohen JN, Prevel N, Sandoval PM, Mathur AN, Moreau JM et al. Regulatory $T$ cells in skin are uniquely poised to suppress profibrotic immune responses. Sci Immunol. 2019. https://doi.org/10.1126/sciimmunol.aaw2910.

114. Gratz IK, Truong H-A, Yang SH-Y, Maurano MM, Lee K, Abbas AK, et al. Cutting Edge: memory regulatory T cells require IL-7 and not IL-2 for their maintenance in peripheral tissues. J Immunol. 2013;190:4483-7.

115. Ali N, Zirak B, Rodriguez RS, Pauli ML, Truong HA, Lai K, et al. Regulatory T cells in skin facilitate epithelial stem cell differentiation. Cell. 2017. https://doi.org/ 10.1016/j.cell.2017.05.002

116. Hussein MRA. Skin metastasis: a pathologist's perspective. J Cutan Pathol. 2010;37:1-20.

117. Spranger S, Spaapen RM, Zha Y, Williams J, Meng Y, Ha TT, et al. Up-regulation of PD-L1, IDO, and T(regs) in the melanoma tumor microenvironment is driven by CD8(+) T cells. Sci Transl Med. 2013;5:200ra116.
118. Lai C, August S, Albibas A, Behar R, Cho S-Y, Polak ME, et al. OX40+ regulatory $T$ cells in cutaneous squamous cell carcinoma suppress effector T-cell responses and associate with metastatic potential. Clin Cancer Res. 2016;22:4236-48.

119. Schulman JM, Pauli ML, Neuhaus IM, Sanchez Rodriguez R, Taravati K, Shin US, et al. The distribution of cutaneous metastases correlates with local immunologic milieu. J Am Acad Dermatol. 2016;74:470-6.

120. Lowe MM, Boothby I, Clancy S, Ahn RS, Liao W, Nguyen DN et al. Regulatory T cells use arginase 2 to enhance their metabolic fitness in tissues. JCI Insight 2019. https://doi.org/10.1172/jci.insight.129756.

121. Oh E, Hong J, Yun C-O. Regulatory T cells induce metastasis by increasing Tgf- $\beta$ and enhancing the epithelial-mesenchymal transition. Cells. 2019;8:1387.

122. Nakamura $Y$, Zhenjie Z, Oya K, Tanaka R, Ishitsuka $Y$, Okiyama N, et al. Poor lymphocyte infiltration to primary tumors in acral lentiginous melanoma and mucosal melanoma compared to cutaneous melanoma. Front Oncol. 2020;10:1-7.

123. Petrova TV, Koh GY. Biological functions of lymphatic vessels. Science. 2020;369: eaax4063.

124. Nadafi R, Gago de Graça C, Keuning ED, Koning JJ, de Kivit S, Konijn T, et al. Lymph node stromal cells generate antigen-specific regulatory $T$ cells and control autoreactive T and B cell responses. Cell Rep. 2020;30:4110-4123.e4.

125. Fahlquist Hagert C, Degn SE. T follicular regulatory cells: guardians of the germinal centre? Scand J Immunol. 2020;92:1-8.

126. Tong A, Forestell B, Murphy DV, Nair A, Allen F, Mandl JN, et al. Regulatory T cells exhibit distinct lymph node homing and trafficking kinetics as compared to conventional CD4+ T cells. J Immunol. 2017;198:215.14-215.14.

127. Spitzer MH, Carmi Y, Reticker-Flynn NE, Kwek SS, Madhireddy D, Martins MM, et al. Systemic immunity is required for effective cancer immunotherapy. Cell. 2017;0:E108-6822

128. Schneider T, Kimpfler S, Warth A, Schnabel PA, Dienemann H, Schadendorf $D$ et al. Foxp3(+) regulatory $T$ cells and natural killer cells distinctly infiltrate primary tumors and draining lymph nodes in pulmonary adenocarcinoma. J Thorac Oncol. 2011;6:432-8.

129. Núñez NG, Tosello Boari J, Ramos RN, Richer W, Cagnard N, Anderfuhren CD et al. Tumor invasion in draining lymph nodes is associated with Treg accumulation in breast cancer patients. Nat Commun. 2020;11:3272.

130. Kazama K, Otake J, Satoyoshi T, Shiozawa M, Sugano N, Sato S, et al. Distribution of regulatory T-cells and other phenotypes of T-cells in tumors and regional lymph nodes of colorectal cancer patients. Vivo. 2020;34:849-56.

131. Louveau A, Harris TH, Kipnis J. Revisiting the mechanisms of CNS immune privilege. Trends Immunol. 2015;36:569-77.

132. Negi N, Das BK. CNS: not an immunoprivilaged site anymore but a virtual secondary lymphoid organ. Int Rev Immunol. 2018;37:57-68.

133. Zhu X, McDowell MM, Newman WC, Mason GE, Greene S, Tamber MS Severe cerebral edema following nivolumab treatment for pediatric glioblastoma: case report. J Neurosurg Pediatr. 2017. https://doi.org/10.3171/2016.8.PEDS16326.

134. Torre M, Solomon IH, Sutherland CL, Nikiforow S, DeAngelo DJ, Stone RM et al. Neuropathology of a case with fatal CAR T-cell-associated cerebral edema. J Neuropathol Exp Neurol. https://doi.org/10.1093/jnen/nly064.

135. Danikowski KM, Jayaraman S, Prabhakar BS. Regulatory T cells in multiple sclerosis and myasthenia gravis. J Neuroinflamm. 2017. https://doi.org/10.1186/ s12974-017-0892-8

136. Venken K, Hellings N, Hensen K, Rummens JL, Medaer R, D'Hooghe MB et al. Secondary progressive in contrast to relapsing-remitting multiple sclerosis patients show a normal $\mathrm{CD} 4+\mathrm{CD} 25+$ regulatory T-cell function and FOXP3 expression. J Neurosci Res. 2006. https://doi.org/10.1002/jnr.20852.

137. Zhang H, Podojil JR, Chang J, Luo X, Miller SD. TGF- $\beta$-induced myelin peptidespecific regulatory $T$ cells mediate antigen-specific suppression of induction of experimental autoimmune encephalomyelitis. J Immunol. 2010. https://doi.org/ 10.4049/jimmunol.0904044.

138. Liesz A, Suri-Payer E, Veltkamp C, Doerr H, Sommer C, Rivest S et al. Regulatory $\mathrm{T}$ cells are key cerebroprotective immunomodulators in acute experimental stroke. Nat Med. 2009. https://doi.org/10.1038/nm.1927.

139. Ito $M$, Komai $K$, Mise-Omata $S$, lizuka-Koga $M$, Noguchi $Y$, Kondo $T$ et al. Brain regulatory $T$ cells suppress astrogliosis and potentiate neurological recovery. Nature 2019. https://doi.org/10.1038/s41586-018-0824-5.

140. Long GV, Atkinson V, Lo S, Sandhu S, Guminski AD, Brown MP et al. Combination nivolumab and ipilimumab or nivolumab alone in melanoma brain metastases: a multicentre randomised phase 2 study. Lancet Oncol. 2018. https://doi.org/ 10.1016/S1470-2045(18)30139-6.

141. Reardon DA, Omuro A, Brandes AA, Rieger J, Wick A, Sepulveda J et al. Randomized phase 3 study evaluating the efficacy and safety of nivolumab vs bevacizumab in patients with recurrent glioblastoma: CheckMate 143. Neurooncology 2017. https://doi.org/10.1093/neuonc/nox036.071.

142. Sugihara Quasar A, Rolle EC, Lesniak SM. Regulatory T cells actively infiltrate metastatic brain tumors. Int J Oncol. 2009;34:1533-40. 
143. Li YD, Lamano JB, Lamano JB, Quaggin-Smith J, Veliceasa D, Kaur G, et al. Tumor-induced peripheral immunosuppression promotes brain metastasis in patients with non-small cell lung cancer. Cancer Immunol Immunother. 2019;68:1501-13.

144. Wainwright DA, Dey M, Chang A, Lesniak MS. Targeting tregs in malignant brain cancer: overcoming IDO. Front Immunol. 2013:4:1-17.

145. Hu X, Deng Q, Ma L, Li Q, Chen Y, Liao Y, et al. Meningeal lymphatic vessels regulate brain tumor drainage and immunity. Cell Res. 2020. https://doi.org/ 10.1038/s41422-020-0287-8

146. Kesarwani P, Prabhu A, Kant S, Chinnaiyan P. Metabolic remodeling contributes towards an immune-suppressive phenotype in glioblastoma. Cancer Immunol Immunother. 2019;68:1107-20.

147. Wainwright DA, Balyasnikova IV, Chang AL, Ahmed AU, Moon KS, Auffinger B et al. IDO expression in brain tumors increases the recruitment of regulatory T cells and negatively impacts survival. Clin Cancer Res. 2012. https://doi.org/ 10.1158/1078-0432.CCR-12-2130.

148. Ueda R, Fujita M, Zhu X, Sasaki K, Kastenhuber ER, Kohanbash G et al. Systemic inhibition of transforming growth factor- $\beta$ in glioma-bearing mice improves the therapeutic efficacy of glioma-associated antigen peptide vaccines. Clin Cancer Res. 2009. https://doi.org/10.1158/1078-0432.CCR-09-1067.

149. Petrelli F, Signorelli D, Ghidini M, Ghidini A, Pizzutilo EG, Ruggieri L et al. Association of steroids use with survival in patients treated with immune checkpoint inhibitors: a systematic review and meta-analysis. Cancers 2020. https://doi.org/10.3390/cancers12030546.

150. Freier E, Weber CS, Nowottne U, Horn C, Bartels K, Meyer S et al. Decrease of CD4+FOXP3 $+\mathrm{T}$ regulatory cells in the peripheral blood of human subjects undergoing a mental stressor. Psychoneuroendocrinology 2010. https://doi.org/ 10.1016/j.psyneuen.2009.10.005

151. Harpaz I, Abutbul S, Nemirovsky A, Gal R, Cohen H, Monsonego A. Chronic exposure to stress predisposes to higher autoimmune susceptibility in C57BL/6 mice: glucocorticoids as a double-edged sword. Eur J Immunol. 2013;43:758-69.

152. Georgantzoglou N, Kokkali S, Tsourouflis G, Theocharis S. Tumor microenvironment in adrenocortical carcinoma: barrier to immunotherapy success? Cancers. 2021;13:1-19.

153. Cohen $R$, Jonchère $V$, De La Fouchardière $C$, Ratovomanana $T$, Letourneur $Q$, Ayadi $M$, et al. Adrenal gland as a sanctuary site for immunotherapy in patients with microsatellite instability-high metastatic colorectal cancer. J Immunother Cancer. 2021;9:1-4

154. Onizuka S, Tawara I, Shimizu J, Sakaguchi S, Fujita T, Nakayama E. Tumor rejection by in vivo administration of anti-CD25 (interleukin-2 receptor a) monoclonal antibody. Cancer Res. 1999;59:3128-33.

155. Teng MWL, Swann JB, von Scheidt B, Sharkey J, Zerafa N, McLaughlin N, et al. Multiple antitumor mechanisms downstream of prophylactic regulatory T-cell depletion. Cancer Res. 2010;70:2665-74.

156. Tanaka A, Sakaguchi S. Targeting Treg cells in cancer immunotherapy. Eur J Immunol. 2019:49:1140-6.

157. Selby MJ, Engelhardt JJ, Quigley M, Henning KA, Chen T, Srinivasan M, et al. Anti-CTLA-4 antibodies of IgG2a isotype enhance antitumor activity through reduction of intratumoral regulatory T cells. Cancer Immunol Res. 2013;1:32-42.

158. Ha D, Tanaka A, Kibayashi T, Tanemura A, Sugiyama D, Wing JB, et al. Differential control of human Treg and effector T cells in tumor immunity by Fc-engineered anti-CTLA-4 antibody. Proc Natl Acad Sci USA. 2019;116:609-18.

159. Sugiyama D, Nishikawa $H$, Maeda $Y$, Nishioka M, Tanemura A, Katayama I, et al. Anti-CCR4 mAb selectively depletes effector-type FoxP3+CD4+ regulatory T cells, evoking antitumor immune responses in humans. Proc Natl Acad Sci USA. 2013;110:17945-50.

160. Bulliard $Y$, Jolicoeur R, Windman M, Rue SM, Ettenberg S, Knee DA, et al. Activating $F_{c} \gamma$ receptors contribute to the antitumor activities of immunoregulatory receptor-targeting antibodies. J Exp Med. 2013;210:1685-93.

161. Arce Vargas F, Furness AJS, Solomon I, Joshi K, Mekkaoui L, Lesko MH, et al. Fcoptimized anti-CD25 depletes tumor-infiltrating regulatory $\mathrm{T}$ cells and synergizes with PD-1 blockade to eradicate established tumors. Immunity. 2017;46:577-86.

162. Bulliard Y, Jolicoeur R, Zhang J, Dranoff G, Wilson NS, Brogdon JL. OX40 engagement depletes intratumoral Tregs via activating FcyRs, leading to antitumor efficacy. Immunol Cell Biol. 2014;92:475-80.

163. Fransen MF, Schoonderwoerd M, Knopf $P$, Camps MGM, Hawinkels LJAC, Kneilling $M$ et al. Tumor-draining lymph nodes are pivotal in PD-1/PD-L1 checkpoint therapy. JCI Insight 2018;3.

164. van Hooren L, Sandin LC, Moskalev I, Ellmark P, Dimberg A, Black P, et al. Local checkpoint inhibition of CTLA-4 as a monotherapy or in combination with antiPD1 prevents the growth of murine bladder cancer. Eur J Immunol. 2017:47:385-93.

165. Ko K, Yamazaki S, Nakamura K, Nishioka T, Hirota K, Yamaguchi T, et al. Treatment of advanced tumors with agonistic anti-GITR mAb and its effects on tumor-infiltrating Foxp3 $+\mathrm{CD} 25+\mathrm{CD} 4+$ regulatory $\mathrm{T}$ cells. J Exp Med. 2005:202:885-91.

166. Sato K, Sato N, Xu B, Nakamura Y, Nagaya T, Choyke PL, et al. Spatially selective depletion of tumor-associated regulatory $\mathrm{T}$ cells with near-infrared photoimmunotherapy. Sci Transl Med. 2016;8:352ra110.

167. Pegram HJ, Lee JC, Hayman EG, Imperato GH, Tedder TF, Sadelain M, et al. Tumor-targeted $\mathrm{T}$ cells modified to secrete IL-12 eradicate systemic tumors without need for prior conditioning. Blood. 2012;119:4133-41.

168. Shabaneh TB, Molodtsov AK, Steinberg SM, Zhang P, Torres GM, Mohamed GA, et al. Oncogenic BRAFV600E governs regulatory T-cell recruitment during melanoma tumorigenesis. Cancer Res. 2018;78:5038-49.

169. Ni X, Jorgensen JL, Goswami M, Challagundla P, Decker WK, Kim YH, et al. Reduction of regulatory $\mathrm{T}$ cells by mogamulizumab, a defucosylated anti-CC chemokine receptor 4 antibody, in patients with aggressive/refractory mycosis fungoides and Sézary syndrome. Clin Cancer Res. 2015;21:274-85.

170. Walker R, Poleszczuk J, Pilon-Thomas S, Kim S, Anderson A, Czerniecki BJ, et al. Immune interconnectivity of anatomically distant tumors as a potential mediator of systemic responses to local therapy. Sci Rep. 2018;8:9474.

171. Krall JA, Reinhardt F, Mercury OA, Pattabiraman DR, Brooks MW, Dougan M, et al. The systemic response to surgery triggers the outgrowth of distant immunecontrolled tumors in mouse models of dormancy. Sci Transl Med. 2018;10.

172. Sun Z, Du C, Xu P, Miao C. Surgical trauma-induced CCL18 promotes recruitment of regulatory $T$ cells and colon cancer progression. J Cell Physiol. 2019;234:4608-16.

173. Predina J, Eruslanov E, Judy B, Kapoor V, Cheng G, Wang LC, et al. Changes in the local tumor microenvironment in recurrent cancers may explain the failure of vaccines after surgery. Proc Natl Acad. Sci USA. 2013;110:415-24.

174. Palma DA, Olson R, Harrow S, Gaede S, Louie AV, Haasbeek C, et al. Stereotactic ablative radiotherapy versus standard of care palliative treatment in patients with oligometastatic cancers (SABR-COMET): a randomised, phase 2, open-label trial. Lancet. 2019;393:2051-8.

175. Schuler PJ, Harasymczuk M, Schilling B, Saze Z, Strauss L, Lang S, et al. Effects of adjuvant chemoradiotherapy on the frequency and function of regulatory T cells in patients with head and neck cancer. Clin Cancer Res. 2013;19:6585-96.

176. Napolitano M, D'Alterio C, Cardone E, Trotta AM, Pecori B, Rega D et al. Peripheral myeloid-derived suppressor and T regulatory PD-1 positive cells predict response to neoadjuvant short-course radiotherapy in rectal cancer patients. Oncotarget 2015. https://doi.org/10.18632/oncotarget.3014.

177. Mota Reyes C, Teller S, Muckenhuber A, Konukiewitz B, Safak O, Weichert W, et al. Neoadjuvant therapy remodels the pancreatic cancer microenvironment via depletion of protumorigenic immune cells. Clin Cancer Res. 2020;26:220-31.

178. Wirsdörfer F, Cappuccini F, Niazman M, Leve S, Westendorf AM, Lüdemann L, et al. Thorax irradiation triggers a local and systemic accumulation of immunosuppressive CD4+ FoxP3+ regulatory T cells. Radiat Oncol. 2014;9:98.

179. Reijmen E, Mey SD, Mey WD, Gevaert T, Ridder KD, Locy H, et al. Fractionated radiation severely reduces the number of $\mathrm{CD} 8(+) \mathrm{T}$ cells and mature antigen presenting cells within lung tumors. Int J Radiat Oncol Biol Phys. 2021;111:27283.

180. Morisada M, Clavijo PE, Moore E, Sun L, Chamberlin M, Waes CV, et al. PD-1 blockade reverses adaptive immune resistance induced by high-dose hypofractionated but not low-dose daily fractionated radiation. Oncoimmunology. 2018;7:1395996.

181. Takenaka W, Takahashi Y, Tamari K, Minami K, Katsuki S, Seo Y et al. Radiation dose escalation is crucial in anti-CTLA-4 antibody therapy to enhance local and distant antitumor effect in murine osteosarcoma. Cancers 2020;12.

182. Liao C, Xiao W, Zhu N, Liu Z, Yang J, Wang Y, et al. Radiotherapy suppressed tumor-specific recruitment of regulator $T$ cells via up-regulating microR-545 in Lewis lung carcinoma cells. Int J Clin Exp Pathol. 2015;8:2535-44.

183. Muroyama Y, Nirschl TR, Kochel CM, Lopez-Bujanda Z, Theodros D, Mao W, et al. Stereotactic radiotherapy increases functionally suppressive regulatory $T$ cells in the tumor microenvironment. Cancer Immunol Res. 2017;5:992-1004.

184. Thomas DA, Massagué J. TGF-beta directly targets cytotoxic T cell functions during tumor evasion of immune surveillance. Cancer Cell. 2005;8:369-80.

185. Formenti SC, Lee $P$, Adams S, Goldberg JD, Li X, Xie MW et al. Focal Irradiation and Systemic TGF $\beta$ Blockade in 2018.

186. Kachikwu EL, Iwamoto KS, Liao YP, DeMarco JJ, Agazaryan N, Economou JS, et al. Radiation enhances regulatory T cell representation. Int J Radiat Oncol Biol Phys. 2011;81:1128-35.

187. Twyman-Saint Victor C, Rech AJ, Maity A, Rengan R, Pauken KE, Stelekati E, et al. Radiation and dual checkpoint blockade activate non-redundant immune mechanisms in cancer. Nature. 2015;520:373-7.

188. Lang X, Green MD, Wang W, Yu J, Choi JE, Jiang L, et al. Radiotherapy and immunotherapy promote tumoral lipid oxidation and ferroptosis via synergistic repression of SLC7A11. Cancer Discov. 2019;9:1673-85. 
189. Welsh JW, Tang C, Groot P, Naing A, Hess KR, Heymach JV, et al. Phase II trial of ipilimumab with stereotactic radiation therapy for metastatic disease: outcomes, toxicities, and low-dose radiation-related abscopal responses. Cancer Immunol Res. 2019;7:1903-9.

190. Kohno M, Murakami J, Wu L, Chan ML, Yun Z, Cho BCJ, et al. Foxp3(+) regulatory $T$ cell depletion after nonablative oligofractionated irradiation boosts the abscopal effects in murine malignant mesothelioma. J Immunol. 2020;205:2519-31.

191. Murakami J, Wu L, Kohno M, Chan ML, Zhao Y, Yun Z, et al. Triple-modality therapy maximizes antitumor immune responses in a mouse model of mesothelioma. Sci Transl Med. 2021;13.

192. Chang WI, Han MG, Kang MH, Park JM, Kim EE, Bae J, et al. PI3Ka $\delta$ inhibitor combined with radiation enhances the antitumor immune effect of anti-PD1 in a syngeneic murine triple-negative breast cancer model. Int J Radiat Oncol. 2021;110:845-58.

193. Panduro M, Benoist C, Mathis D. Tissue Tregs. Annu Rev Immunol. 2016;34:609-33.

\section{COMPETING INTERESTS}

A.D.: Consultant, BMS, Merck, Pfizer, Novartis, Incyte, Checkmate, Eisai. Research Funding: OncoSec, Pfizer, Merck, Novartis, GSK, BioNTech, Replimune, Exicure. Stock: TRex Bio, NEUVOGEN. The remaining authors declare no competing interests.

\section{ADDITIONAL INFORMATION}

Correspondence and requests for materials should be addressed to J.C.L.

Reprints and permission information is available at http://www.nature.com/ reprints

cc) (i) Open Access This article is licensed under a Creative Commons Attribution 4.0 International License, which permits use, sharing adaptation, distribution and reproduction in any medium or format, as long as you give appropriate credit to the original author(s) and the source, provide a link to the Creative Commons license, and indicate if changes were made. The images or other third party material in this article are included in the article's Creative Commons license, unless indicated otherwise in a credit line to the material. If material is not included in the article's Creative Commons license and your intended use is not permitted by statutory regulation or exceeds the permitted use, you will need to obtain permission directly from the copyright holder. To view a copy of this license, visit http://creativecommons. org/licenses/by/4.0/.

(c) The Author(s) 2021 